\title{
Emotional and Behavioral Correlates of Mediodorsal Thalamic Neurons during Associative Learning in Rats
}

\author{
Tatsuki Oyoshi, ${ }^{2}$ Hisao Nishijo, ${ }^{1}$ Tetsuhiko Asakura,, ${ }^{2}$ Yusaku Takamura, ${ }^{1}$ and Taketoshi Ono' \\ ${ }^{1}$ Department of Physiology, Faculty of Medicine, Toyama Medical and Pharmaceutical University, Sugitani 2630, Toyama \\ 930-01, Japan, and 2Department of Neurosurgery, Faculty of Medicine, Kagoshima University, Kagoshima 890, Japan
}

Neuronal activity was recorded from the mediodorsal thalamic nucleus (MD) of behaving rats that were trained to lick a protruding spout just after a conditioned stimulus to obtain reward or to avoid shock. Conditioned stimuli included both elemental (auditory or visual stimuli) and configural (simultaneous presentation of auditory and visual stimuli predicting reward outcome opposite that predicted by each stimulus presented alone) stimuli. Of $122 \mathrm{MD}$ neurons responding during the task, the activity of 13 increased just before licking only during the task, but not before spontaneous licking during the intertrial interval (conditioned behavior related). These conditioned behaviorrelated neurons were located mainly in the lateral MD, which has intimate anatomical connections with motor-related areas such as anterior cingulate and striatum. The activity of the other 109 neurons was related to conditioned stimulation (conditioned stimulus related). Most of these neurons responded differentially to both elemental and configural stimuli in terms of reward contingency, and also changed their responses during extinction and relearning trials. Conditioned stimulus-related neurons with latencies $<300$ msec were located mainly in the rostromedial $\mathrm{MD}$, which receives afferents from the basolateral nucleus of the amygdala in which sensory information from various sources converge. Furthermore, most differential neurons that were tested responded during the delay period in a reward task in which a delay was imposed between the conditioned stimulus and reward delivery. The present results, along with previous anatomical studies, suggest the existence of two limbic circuits: anterior cingulate-striatum-lateral MD (motor) and amygdala-medial MD-orbital prefrontal cortex (short-term memory/emotion).

Key words: mediodorsal thalamic nucleus; conditioning; neuronal activity; learning; emotionality; motor behavior
The mediodorsal thalamic nucleus (MD) is a prominent part of the thalamus of all mammals and is most highly developed in humans (Le Gros Clark, 1932a,b). It has been suggested that the MD is involved in various higher brain functions such as learning and memory processes as well as emotion. Patients with diencephalic lesions that include the MD manifest Korsakoff's syndrome, with global amnesia and various emotional changes (Schulman, 1957; Victor et al., 1971). Neuropsychological studies in animals and humans indicate that the MD is one of the areas responsible for diencephalic amnesia (Squire and Moore, 1979; Aggleton and Mishkin, 1983; Graff-Radford et al., 1985; Zola-Morgan and Squire, 1985) and deficits in working memory (Isseroff et al., 1982). MD lesions also induce changes in emotionality (Schulman, 1957; Butter and Snyder, 1972; Waring and Means, 1976) or deficits in associating a stimulus with reinforcement (Gaffan et al., 1993). Furthermore, cerebral blood flow in a rostromedial MD increased in depressed patients (Drevets, 1995). These extensive studies indicate the functional diversity of the MD.

Anatomically, the MD is located in a position where motor, cognitive, and motivational or emotional systems converge. The MD has intimate topographic and reciprocal connections with the

Received Jan. 25, 1996; revised June 6, 1996; accepted June 12, 1996.

This work was supported partially by the Japanese Ministry of Education, Science and Culture Grants-in-Aid for Scientific Research (08408036, 08279105, 08279215, 08234209 , and 08680884 ), and by the Uehara Memorial Foundation. We thank Dr. M. Davis, Departments of Psychology and Psychiatry, Yale University School of Medicine, for helpful comments on this manuscript.

Correspondence should be addressed to Dr. Taketoshi Ono, Department of Physiology, Faculty of Medicine, Toyama Medical and Pharmaceutical University, Sugitani 2630, Toyama 930-01, Japan.

Copyright (C) 1996 Society for Neuroscience $0270-6474 / 96 / 165812-18 \$ 05.00 / 0$ dorsolateral prefrontal cortex (Leonard, 1969; Krettek and Price, 1977; Ray and Price, 1992) and with the limbic cortices such as the cingulate, the orbital cortex, and the temporal pole (GoldmanRakic and Porrino, 1985; Groenewegen, 1988). It also receives projections from subcortical structures such as the striatum, basal forebrain, amygdala, and brainstem (Aggleton and Mishkin, 1984; Groenewegen, 1988). These complex connections have been viewed in terms of two functionally distinct limbic circuits. One, implicated in emotion, is the basolateral limbic circuit (Krettek and Price, 1977; Sarter and Markowitsch, 1983, 1984; Bachevalier and Mishkin, 1986; Cassell and Wright, 1986; Gaffan et al., 1993), which includes the amygdala, medial MD, and orbital cortex. The other, implicated in motor function, is the dorsal anterior cingulate circuit (Groenewegen, 1988), which includes the anterior cingulate cortex, dorsomedial striatum, medial portion of the globus pallidus, and lateral MD.

Neurophysiological studies have included both single- and multiple-unit activity in the MD during a delayed response task or visual recognition task in monkeys (Kubota et al., 1972; Fuster and Alexander, 1973; Fahy et al., 1993) and avoidance learning in rabbits (Kubota and Gabriel, 1995); however, no studies thus far have related neuronal activity to the anatomical and functional diversity of the MD (see above). The present study was designed to investigate emotional and motor functions of the MD by recording rat $\mathrm{MD}$ neuronal activity during the performance of conditioned associative tasks. The conditioned stimuli included both elemental (auditory or visual stimuli) and configural (simultaneous presentation of auditory and visual stimuli) stimuli. In one case, each stimulus predicted reward when presented alone but predicted no reward when they were presented together. In 
the other case, each stimulus predicted nonreward when presented alone but predicted reward when they were presented together.

\section{MATERIALS AND METHODS}

Subjects. Fourteen male albino Wistar rats weighing 270-330 gm (SLC, Hamamatsu, Japan) were used. The housing area was temperaturecontrolled at $23^{\circ} \mathrm{C}$ and maintained on a $12 \mathrm{hr}$ light/dark cycle. Before surgery, rats were housed individually in clean cages with free access to water and laboratory chow.

Surgery. Surgery was performed under aseptic conditions in two stages. First, a cranioplastic cap was attached to the skull. After a recovery and a training period, a permanent indifferent electrode was implanted. All rats were treated in strict compliance with the United States Public Health Service Policy on Human Care and Use of Laboratory Animals and the National Institutes of Health Guide for the Care and Use of Laboratory Animals.

As described in our previous study (Uwano et al., 1995), the head restraint system of Nishijo and Norgren (1990, 1991), modified from a method described by Ono et al. (1985), was used. The rat was anesthetized (sodium pentobarbital, $40 \mathrm{mg} / \mathrm{kg}$, i.p.) and then mounted in a stereotaxic apparatus with its skull level between the bregma and lambda suture points. The cranium was exposed, $2-3 \mathrm{~mm}$ of the temporal end of the temporal muscle was removed bilaterally, and seven small sterile stainless screws were then threaded into holes in the skull to serve as anchors for cranioplastic acrylic. Stainless steel wires were soldered onto two screws to serve as a ground. Two bipolar electrodes for intracranial stimulation were implanted in the medial forebrain bundle (anterior, -5.2 from bregma; lateral, \pm 0.8 ; ventral, 8.2), according to the atlas of Paxinos and Watson (1986). After the cut end of the temporal muscle was covered with the overlying skin, the cranioplastic acrylic was built up on the skull and molded around the conical ends of two sets of stainless steel bars that had a single steel bar on one end and two bars on the other end. Once the cement had hardened, these bars were removed, leaving a negative impression of the double end on each side of the acrylic block. During subsequent surgery or during the recording session, the double end of these artificial earbars was pressed into the indentations in the acrylic block, and the single end was inserted into the normal earbar slots in the stereotaxic instrument and attached rigidly to the stereotaxic. Hence, these artificial earbars served the same function as regular earbars but could be used in the unanesthetized animal (Fig. 1A) because they did not involve painful insertion into the ear canal. A short length of 27 gauge stainless steel tubing was embedded in the cranioplastic acrylic near bregma to serve as a reference pin during chronic recording.

Two stainless wires (50 $\mu \mathrm{m}$ diameter) were inserted into the genioglossus muscle to monitor tongue movements. The electromyogram (EMG) wires were brought out subcutaneously to the skull and anchored to the cranioplastic cap. After surgery, an antibiotic (gentamicine sulfate, Gentacin Injection, Schering-Plough, Osaka, Japan) was administered topically and systemically ( $2 \mathrm{mg}$, i.m.).

After recovery from surgery (10-14 d) and after training ( 2 weeks) (see below), rats were anesthetized (sodium pentobarbital, $40 \mathrm{mg} / \mathrm{kg}$, i.p.), and the artificial earbars were mounted. A hole (3-5 mm diameter) for chronic recording was drilled through the cranioplastic and the underlying skull (anterior, -1.3 to -4.3 from bregma; lateral, 0.2 to 3.0 right). The exposed dura was excised, and the hole was covered with hydrocortisone ointment (Rinderon-VG ointment, Shionogi, Tokyo, Japan), or one or two drops of chloramphenicol (Chloromycetin Succinate, Sankyo, Tokyo, Japan $)$ solution $(0.1 \mathrm{gm} / \mathrm{ml})$ were dropped in the hole. The hole was covered with a sterile Teflon sheet and sealed with an epoxy glue. A second small hole ( $1.5 \mathrm{~mm}$ diameter) was then drilled just contralateral to the hole for recording. A stainless steel wire (130 $\mu \mathrm{m}$ diameter), insulated except at the cross-section of the tip, was implanted near the lateral end of the left MD through the hole to serve as an indifferent electrode. This hole was then filled with cranioplastic acrylic. After the animal recovered (5-7 d), it was placed back on the water-deprivation regimen (see below).

Training and task paradigms. Before surgery, the rats were acclimated by handling and were accustomed to being placed into a small, plastic restraining cage for brief periods. After recovery from the first stage of surgery, the threshold level for intracranial self-stimulation (ICSS) was determined (Ono et al., 1985), and any rat for which the threshold exceeded $300 \mu \mathrm{A}$ was excluded. The remaining rats were reacclimated to the plastic enclosure and placed on a $22 \mathrm{hr}$ water-deprivation regimen.
While in the enclosure (1-2 hr daily), the rats had access to a spout from which they learned to take fluids, initially $0.3 \mathrm{~m}$ sucrose, within 1-2 d. Subsequently, their heads were fixed rigidly and painlessly by inserting the artificial earbars into the impressions in the cranioplastic cap. While the rats were restrained, they were trained to lick a spout, which was automatically extended close to their mouths for $2 \mathrm{sec}$, to obtain sucrose solutions and an ICSS reward. The rats were then trained to discriminate between conditioned elemental (auditory or visual) or configural stimuli to obtain positive rewards or to avoid shock. Sensory stimuli included auditory $(300,530,1200,2860 \mathrm{~Hz})$, visual (white light), and configural (simultaneous presentation of tone and light) stimuli. A mid-range speaker $1 \mathrm{~m}$ above the rats delivered the auditory stimuli, and two white lights $3 \mathrm{~cm}$ in front of each eye delivered the visual stimuli. Licking was signaled by a photoelectric sensor triggered by the tongue. The rat was trained to lick a spout that protruded close to its mouth to obtain reward (sucrose solution or ICSS) (Reward task; Fig. 1B) or to avoid electric shock (Avoidance task; Fig. 1C). A 2.0 sec conditioned tone preceded protrusion of the spout (Table 1). A $2860 \mathrm{~Hz}$ tone (Tone 1), a white light in front of the right eye (Light 1), or simultaneous presentation of a 530 $\mathrm{Hz}$ tone (Tone 2) and a white light in front of the left eye (Light 2) (Tone $2+$ Light 2: configural stimulus) signaled availability of $0.3 \mathrm{~m}$ sucrose solution. A $1200 \mathrm{~Hz}$ tone (Tone 3) signaled ICSS $(0.5 \mathrm{sec}$ train of $100 \mathrm{~Hz}$, $0.3 \mathrm{msec}$ capacitor-coupled negative square wave pulses). Tone 2 , Light 2 , or simultaneous presentation of Tone 1 and Light 1 (Tone 1+Light 1: configural stimulus) signaled the availability of no reinforcement.

In an avoidance task, the rats were trained initially to lick a spout that was extended automatically for $2 \mathrm{sec}$ without being signaled by any sensory stimulus. If the rat did not lick within $2 \mathrm{sec}$ after spout protrusion, electric shock was delivered. No rewards were delivered during these trials, so any response was made for avoidance only. The rats were then trained to lick the spout within $2 \mathrm{sec}$ when a $300 \mathrm{~Hz}$ tone (Tone 4) was presented to avoid electric shock. The weak electric shock $(0.5 \mathrm{sec}$ train of $100 \mathrm{~Hz}, 0.3 \mathrm{msec}$ capacitor-coupled negative square wave pulses) was given from the grid electrode of the floor under the rat. When the rat learned the reward and avoidance tasks, it was trained further with a reward task with delay, in which a delay was imposed between the auditory stimulus (Tone 1) and protrusion of the spout (Fig. 1D).

Training with either positive or negative reinforcement was carried out separately in one block of 10 or 20 trials. Finally, rats were trained to lick a spout after other conditioned stimuli. The total number of trials per day was $400-500$ in $4 \mathrm{hr}$ from 4-8 P.M. Throughout the training and recording period, a rat was permitted to ingest $20-30 \mathrm{ml}$ of water while it was in the restrainer. If the rat failed to take a total volume of $30 \mathrm{ml}$ water while restrained, it was given the remainder when it was returned in its home cage.

After the rats had learned the tasks described above, MD neurons were recorded during performance of these tasks.

Electrophysiological recording. An individual rat was usually tested every other day. After it was placed in the enclosure, the ointment was removed, and a glass-insulated tungsten microelectrode $(\mathrm{Z}=1.0-1.5 \mathrm{M} \Omega$ at $1000 \mathrm{~Hz}$ ) was stereotaxically inserted stepwise with a pulse motordriven manipulator (SM-20, Narishige, Greenvale, NY) into various parts of the right MD. Extracellular neuronal and EMG activity was passed through a dual-channel differential amplifier with a preamplifier (DPA220, DIA Medical System), monitored on an oscilloscope, and recorded on a data recorder (RT-145T DAT DATA RECORDER, TEAC). Neuronal activity was counted by a two-level voltage discriminator. The analog signal, the trigger levels, and the output of the discriminator were monitored continuously on an oscilloscope during analysis. The discriminator output pulses were accumulated and displayed as peristimulus histograms by an on-line minicomputer (ATAC-450, Nihon Kohden). Another computer (PC-98 $21 \mathrm{Bp}, \mathrm{NEC}$ ) stored the events and times of the trigger signals, output pulses from the discriminator, and lick signals for display of rasters and histograms off line.

Data analysis. Both neuronal and behavioral data on each trial were counted from the peristimulus histograms in successive $80 \mathrm{msec}$ bins for three periods: a pretrial control period $(2.56 \mathrm{sec})$, a conditioned sensory stimulation period $(2 \mathrm{sec})$, and a rewarding or aversive stimulation period $(2 \mathrm{sec})$. Neuronal activities were compared by one-way ANOVA $(p<$ 0.05 ) among discharge rates in the control period, conditioned sensory stimulation periods, a delay period $(2.4 \mathrm{sec}$ in the case of the reward task with delay), and a reinforcement (rewarding or aversive) period ( $2 \mathrm{sec}$ ). Excitatory or inhibitory neuronal responses were determined from the discharge rates in the control periods and those in each conditioned sensory stimulation, delay period, or reinforcement period, by the post 


\section{A Experimental diagram}

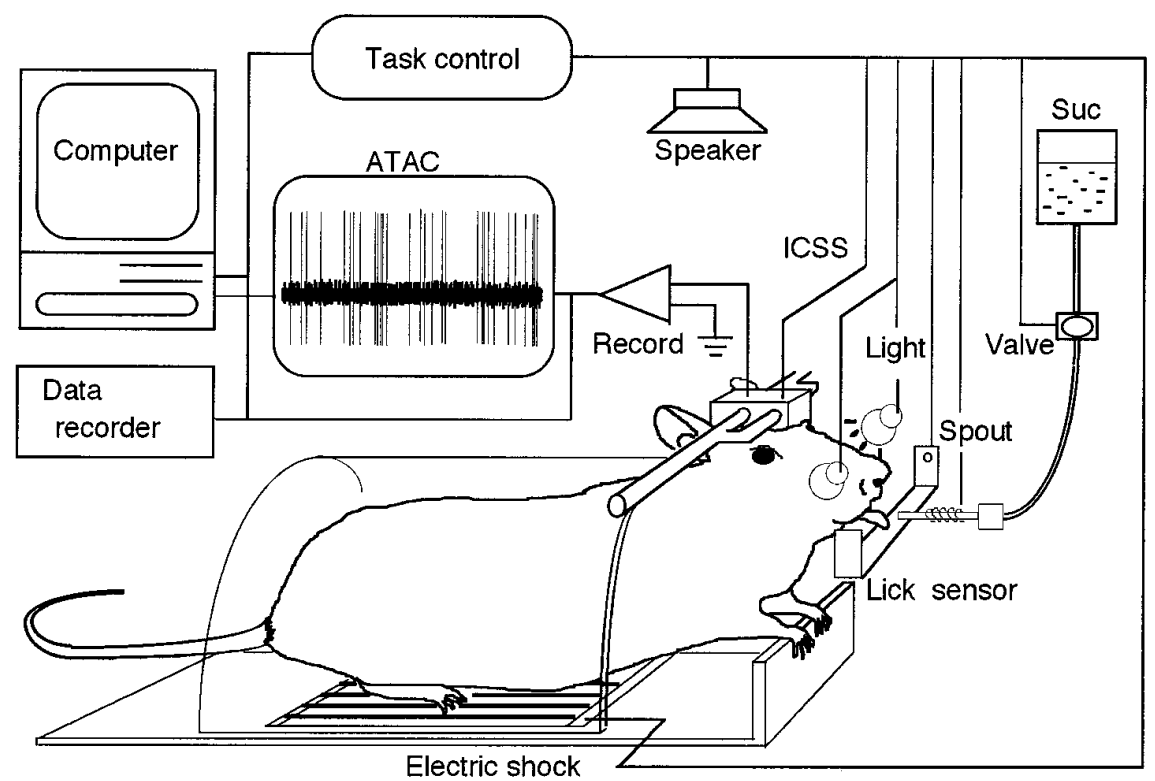

Figure 1. Experimental diagram. A, Rats were prepared for chronic recording by the formation of receptacles of dental cement to accept artificial earbars. Electrodes were implanted in the ventral tegmental area for ICSS. The rat was trained to lick when the spout was automatically placed close to its mouth. Licking was signaled by a photoelectric sensor triggered by the tongue. Electric shock was delivered from the grid on a floor of a restraining cage. $B-D$, Time chart of reward task $(B)$, avoidance task $(C)$, and reward task with delay $(D)$. In the reward associative task, one of conditioned sensory stimuli (tone, light, or configural stimuli) associated with and without rewarding stimulus (ICSS or sucrose solution) was presented for $2.0 \mathrm{sec}$ before the spout was placed close to the rat's mouth $(B)$. In the avoidance task, the rat could avoid electric shock if the spout was licked within $2.0 \mathrm{sec}$ after the conditioned auditory stimulus $(C)$. In the reward task with delay, a conditioned auditory stimulus was presented as in the reward task, but the rat had to wait for a delay period $(2.4 \mathrm{sec})$ before licking a spout. Suc, $0.3 \mathrm{~m}$ sucrose solution.

\section{B Reward task}

$$
\begin{aligned}
& \text { Sensory stimuli } \\
& \text { Lick } \\
& \text { Reward } \\
& \text { (ICSS or Suc) }
\end{aligned}
$$

\section{Avoidance task}

Auditory stimuli

Lick

Electric shock
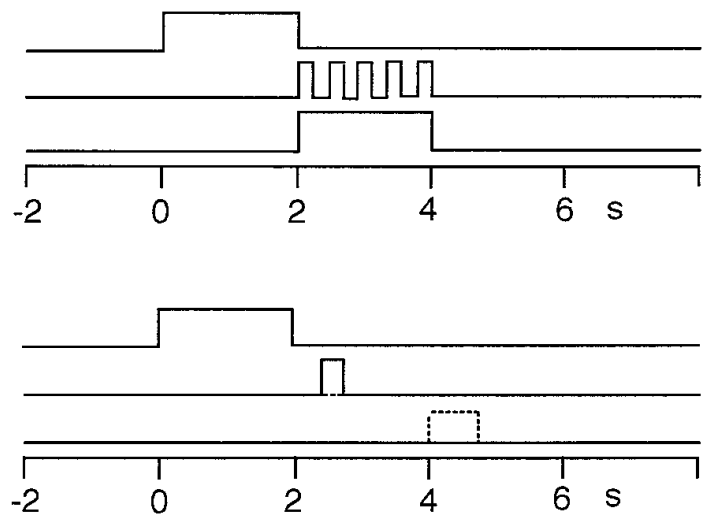

D Reward task with delay

Auditory stimuli
Lick
Reward (Suc)

Auditory stimuli

Reward (Suc)

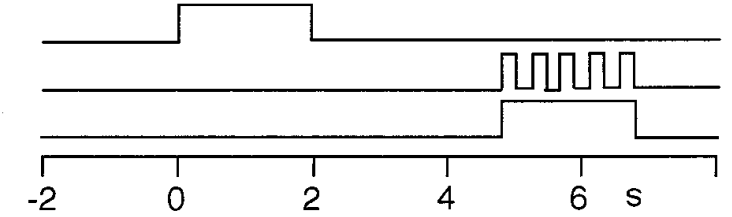

hoc test (Tukey test, $p<0.05$ ). Each neuronal response to each conditioned sensory stimulus was also compared by one-way ANOVA and Tukey test $(p<0.05)$.

The response latency of each neuron that responded during a conditioned sensory stimulation period was defined as the time between the computer-generated, synchronizing trigger signal that represented the onset of sensory stimulation and the time when the firing rate exceeded $2 \mathrm{SD}$ from the mean spontaneous firing rate determined from a histogram with $1-50 \mathrm{msec}$ bins. The spontaneous firing rates and response latencies among various neuronal types were compared by one-way ANOVA and Tukey test $(p<0.05)$.

To analyze relations between neuronal activity and licking behavior, perievent raster displays and accumulated histograms were constructed by aligning the neuronal activity with the EMG onset. The EMG onset was defined as the time when the magnitude of licking-related muscle activity first deviated by $3 \mathrm{SD}$ from the mean value of the background activity (Shima et al., 1991).

Histology. After the last recording session, a rat was anesthetized with sodium pentobarbital $(50 \mathrm{mg} / \mathrm{kg}$, i.p.), and several small electrolytic lesions ( $20 \mu \mathrm{A}$ for $20 \mathrm{sec})$ were made stereotaxically around the recorded sites with a glass-insulated tungsten microelectrode. Rats were then given an additional overdose of anesthetic and perfused transcardially with heparinized $0.9 \%$ saline followed by $10 \%$ buffered formalin. The brain was removed and cut into $50 \mu \mathrm{m}$ frontal sections with a freezing microtome. Sections were stained with cresyl violet. All marking and stimulation sites then were carefully verified microscopically. Positions of neurons were stereotaxically located on the real tissue sections and plotted on the corresponding sections on the atlas of Paxinos and Watson (1986)

Anatomically, the rat MD has been divided into medial (MDM), central (MDC), and lateral segments (MDL) on the basis of cytoarchitectonic criteria and topographically special reciprocal connections with the prefrontal cortex (Leonard, 1969; Krettek and Price, 1977; Ray and Price, 1992). The classification and terminology of these MD subnuclei were determined on the basis of the atlas of Paxinos and Watson (1986). 


\begin{tabular}{ll}
\hline $\begin{array}{l}\text { Table 1. Summary of various conditioned sensory stimuli associated } \\
\text { with or without rewarding or aversive reinforcement }\end{array}$ & \\
Conditioned stimuli & Reinforcement \\
\hline Elemental stimuli & \\
Auditory stimuli & \\
Tone $1(2860 \mathrm{~Hz})$ & Sucrose \\
Tone $2(530 \mathrm{~Hz})$ & No reinforcement \\
Tone $3(1200 \mathrm{~Hz})$ & ICSS \\
Tone $4(300 \mathrm{~Hz})$ & Electric shock \\
Visual stimuli & \\
Light $1($ right $)$ & Sucrose \\
Light $2($ left $)$ & No reinforcement \\
Configural stimuli & \\
Tone $1+$ Light 1 & No reinforcement \\
Tone $2+$ Light 2 & Sucrose \\
\hline
\end{tabular}

Light 1 and light 2 indicate visual stimulation by white lights located in front of right and left eyes, respectively.

\section{RESULTS}

\section{Classification of the MD neurons}

During a period of 1-3 months for each rat, recordings were made from 751 neurons in and around the MD during the various tasks. Of these, 510 neurons were located in the MD, and all 510 neurons were tested at least with the reward task. Table 2 summarizes the response patterns of these 510 neurons. One hundred twenty-two neurons (23.9\%) responded (all, excitatory) in one or more phases of the task. These 122 responsive neurons were classified into two types on the basis of how their firing rates changed during licking or during presentation of sensory stimuli. The activity of 13 neurons $(2.5 \%, 13 / 510)$ was correlated to licking behavior only during the task but not during the intertrial interval (conditioned behavior-related neurons). The activity of the remaining 109 neurons $(21.4 \%, 109 / 510)$ was not correlated to behavioral responses during the task or during the intertrial interval, but instead was correlated to the presentation of sensory

Table 2. Classification of responsive neurons in the rat mediodorsal thalamic nucleus

\begin{tabular}{lcrr} 
& $\begin{array}{l}\text { Sensory stimuli } \\
\text { Classification }\end{array}$ & $n$ & $\%$ \\
\hline Conditioned behavior-related & & 13 & 2.5 \\
Conditioned stimulus-related & & & \\
$\quad$ Differential & Unimodal & 7 & 19.0 \\
& Auditory & 5 & 1.4 \\
& Visual & 2 & 1.0 \\
& Sucrose & 0 & 0.4 \\
& ICSS & 0 & 0.0 \\
& Multimodal & 90 & 17.6 \\
& A + V+I+S & 81 & 15.9 \\
& A+I & 4 & 0.8 \\
& A+V+S & 5 & 1.0 \\
& & 12 & 2.4 \\
$\quad$ Nondifferential & & 122 & 23.9 \\
Total responsive & & 388 & 76.1 \\
Total nonresponsive & & & \\
& & 510 & 100.0 \\
Total recorded & &
\end{tabular}

$n$, Number of neurons responding to a given stimulus. A, Auditory; V, visual; I, ICSS; $\mathrm{S}$, sucrose solution. stimuli (conditioned stimulus-related neurons). Of 109 conditioned stimulus-related neurons, $97(19.0 \%, 97 / 510)$ responded differentially to the conditioned sensory stimuli with or without reinforcement (differential conditioned stimulus-related neurons), and $12(2.4 \%)$ responded nondifferentially (nondifferential conditioned stimulus-related neurons). Of 97 differential conditioned stimulus-related neurons, 7 responded exclusively to auditory or visual stimuli [5 (1.0\%, 5/510), auditory; $2(0.4 \%, 2 / 510)$, visual] (unimodal differential conditioned stimulus-related neurons). The remaining $90(17.6 \%, 90 / 510)$ neurons responded to various conditioned sensory stimuli (multimodal differential conditioned stimulus-related neurons).

\section{Conditioned behavior-related neurons}

The activity of 13 conditioned behavior-related neurons was correlated to behavioral responses only during the task but not during the intertrial interval. A typical example of this type neuron is shown in Figure 2. Figure $2 A, B$ depicts raw records of the neuronal $(a)$ and EMG $(b)$ activities during the task $(A)$ and the intertrial interval $(B)$, respectively. The activity of the neuron increased slightly before the increase in EMG activity because of licking during the task $(A)$; however, there was no correlation between the neuronal and EMG activities during the intertrial interval $(B)$. During the intertrial interval, the activity of the neuron did not increase when EMG activity increased by spontaneous movements of a tongue. To analyze relations between the neuronal and EMG activities during the task, the neuronal discharges were aligned with EMG onset and accumulated (Fig. 2C). In this neuron, the onset of the neuronal responses preceded that of EMG by $35 \mathrm{msec}$.

The conditioned behavior-related neurons were defined as those neurons in which there was a significant difference in their mean firing rates during an $800 \mathrm{msec}$ period before and after the EMG onset (paired $t$ test, $p<0.05$ ). In this neuron, the mean firing rate after EMG onset for $800 \mathrm{msec}$ was significantly larger than that before EMG onset (paired $t$ test, $p<0.05$ ) (Fig. $2 D$ ). Figure $2 E$ shows the distributions of the onset times of the 13 conditioned behavior-related neurons. Onset times of the neuronal responses in reference to EMG onset ranged from -35 to $-160(-91.9 \pm 10.7$, mean \pm SEM; $n=13)$ msec.

\section{Conditioned stimulus-related neurons}

The activity of 109 neurons was not correlated to behavioral responses during the tasks (conditioned stimulus-related neurons). Raw records of this type neuron (multimodal differential conditioned stimulus-related neuron) are illustrated in Figure 3. The neuron responded to Tone $1(A)$, Light $1(C)$, and Tone $2+$ Light $2(D)$ predicting sucrose solution, and to ingestion of sucrose solution, but not to Tone $1+$ Light $1(B)$ and Light $2(E)$ predicting no reinforcement. There was no correlation between the neuronal and EMG activities, because activity of the neuron increased during the sensory stimulation period in the absence of EMG activity $(A, C, D)$. Furthermore, EMG activity increased in the absence of neuronal activity during the intertrial interval $(F)$. The accumulated histogram of the discharges of this neuron aligned with EMG onset is shown in Figure $4 A$. The mean firing rate of this neuron for the $800 \mathrm{msec}$ period before EMG onset was not significantly different from that for the $800 \mathrm{msec}$ period after EMG onset (paired $t$ test, $p>0.05$ ) (Fig. 4B). Similarly, the activity of all 109 conditioned stimulus-related neurons was not correlated to EMG activity during the task or during the intertrial interval (paired $t$ test, $p>0.05$ ). 


\section{A Task-related licking}

\section{Tone 1}

Suc

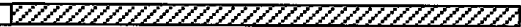

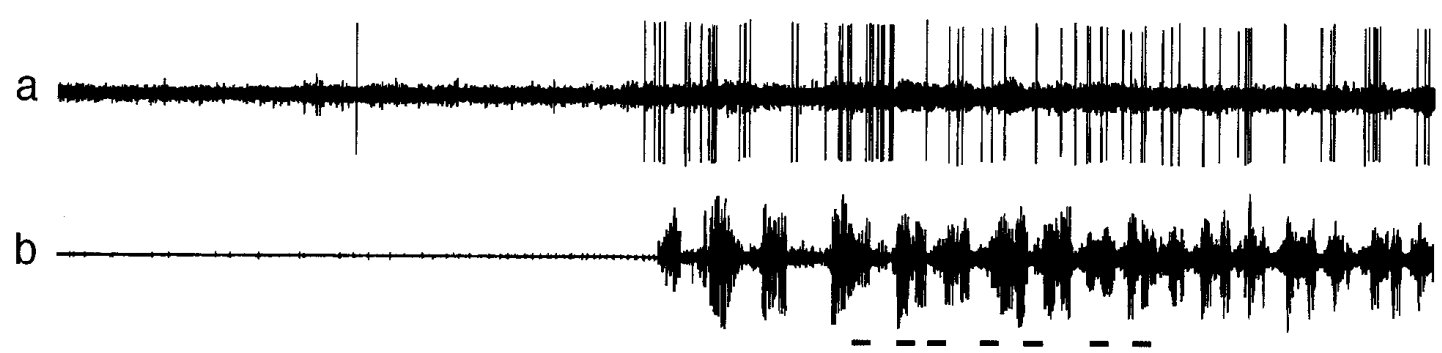

B spontaneous movement
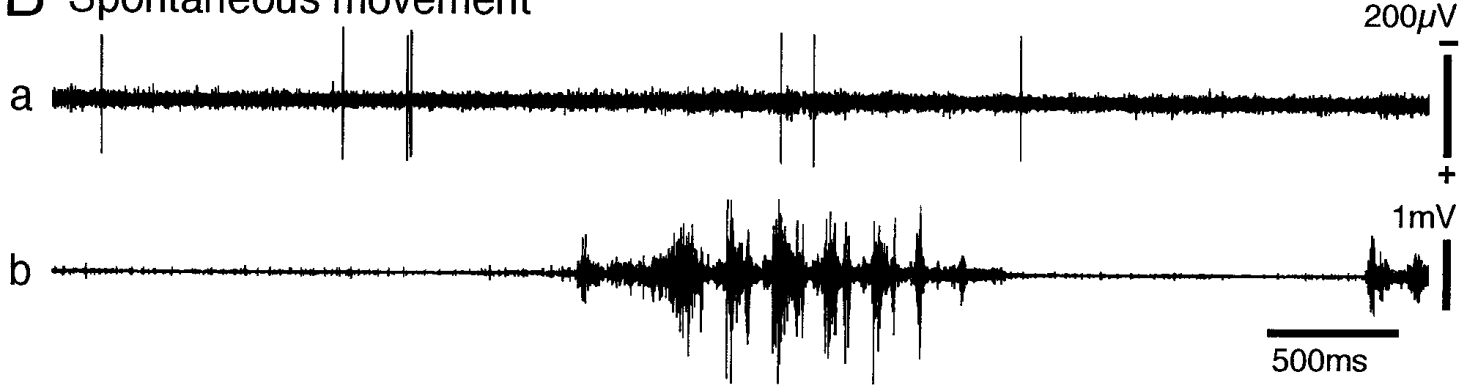

C EMG-triggered

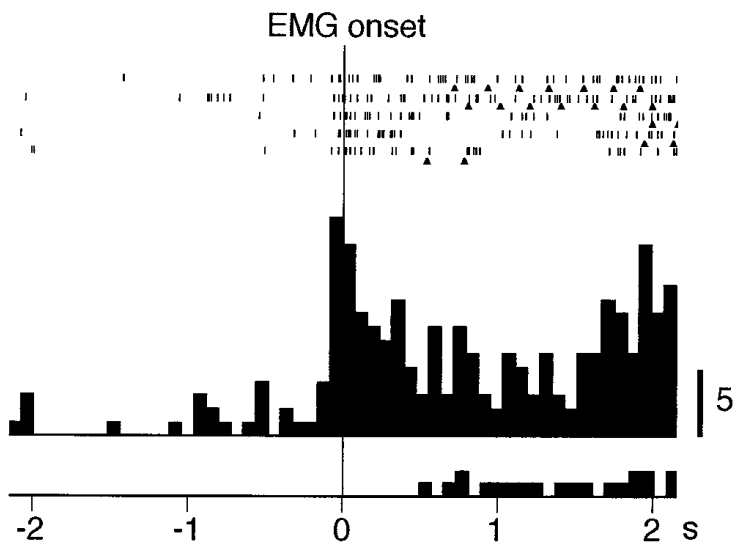

D Neuronal activities before and after EMG onset

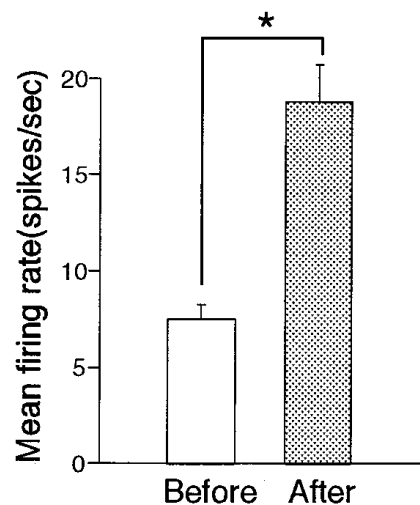

\section{$E$ Onset of neuronal activity preceding EMG onset}

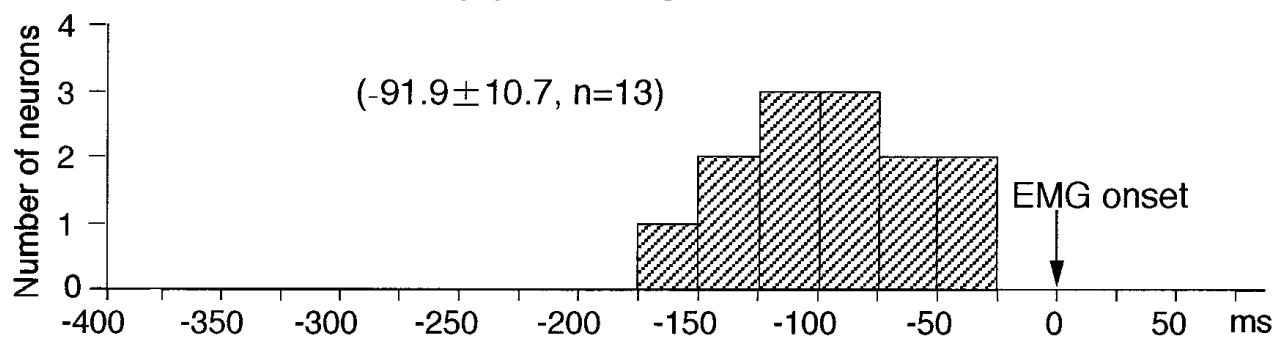

Figure 2. Activity of a conditioned behavior-related neuron. A, Activity of a conditioned behavior-related neuron during the reward task. Raw records indicated by $a$ and $b$ show the neuronal and genioglossus EMG activities, respectively. Open and hatched rectangles at top indicate duration of conditioned stimulus and time of reinforcement, respectively. Each bar below the EMG trace indicates one lick. Neuronal activity increased $35 \mathrm{msec}$ before increase of EMG activity of the genioglossus. $B$, Activity of a conditioned behavior-related neuron during spontaneous movements of a tongue during intertrial interval. Note that EMG activity increased regardless of the neuronal activity. $C$, Raster displays and accumulated histogram of the responses of the conditioned behavior-related neuron shown in $A$ during the reward task. Raster displays and the histogram were aligned with the EMG onset. Each triangle below a raster line indicates one lick. Time scale in seconds; 0 in time scale indicates onset of the genioglossus EMG activity; each histogram bin, $80 \mathrm{msec}$. $D$, Histogram of the mean firing rate for $800 \mathrm{msec}$ before and after the genioglossus EMG onset. Note that the mean firing rate for $800 \mathrm{msec}$ after EMG onset was significantly larger than that before EMG onset (paired $t$ test; $p<0.05$ ). E. Histogram of the onset times of the 13 conditioned behavior-related neurons preceding that of the genioglossus EMG activity. 0 in time scale; onset of the genioglossus EMG activity. Time scale: seconds. 


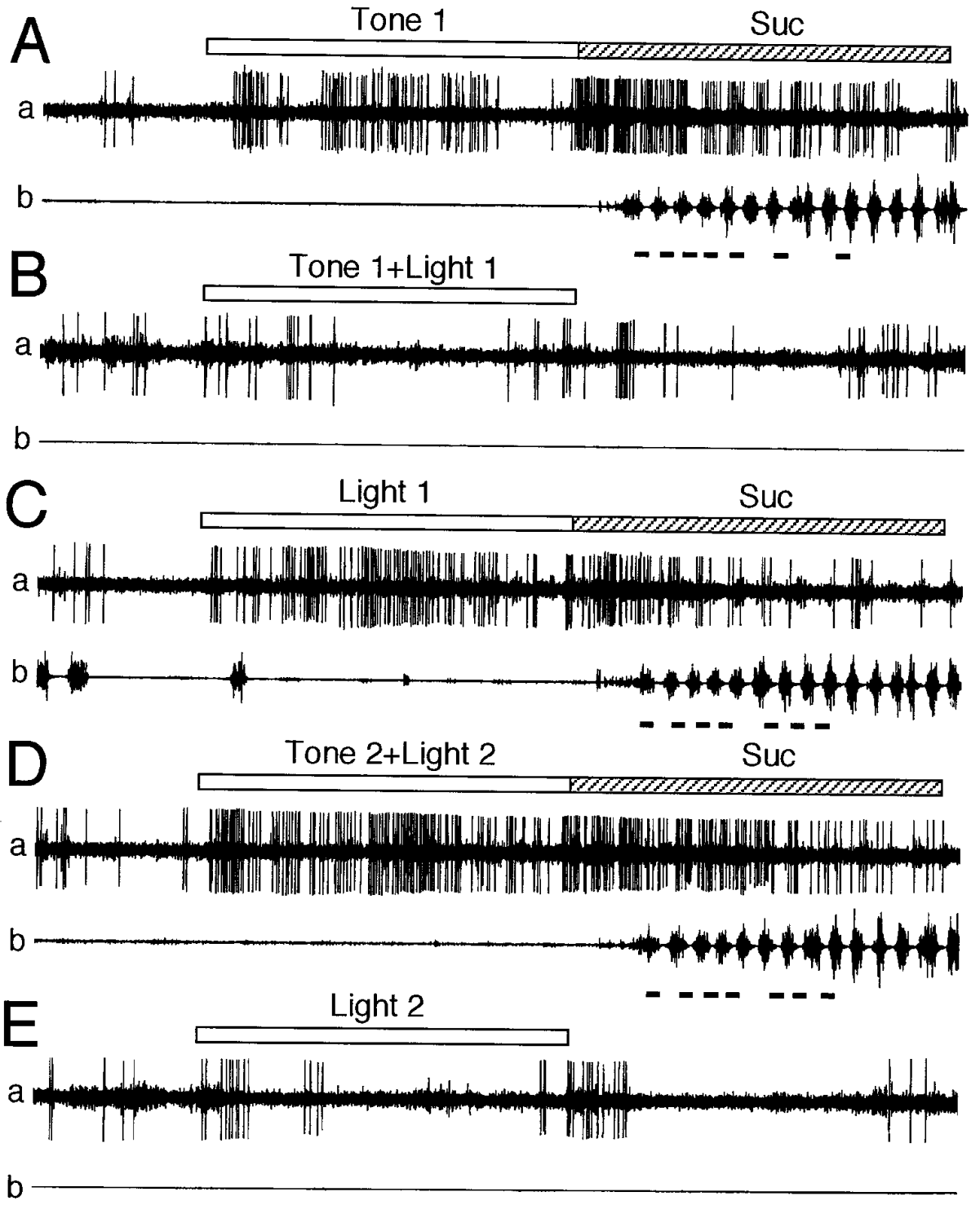

F Spontaneous movement

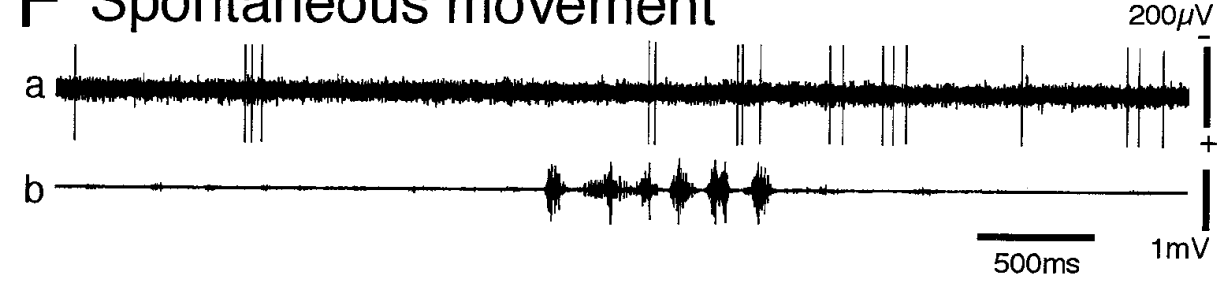

Figure 3. Activity of a differential conditioned stimulus-related neuron. $A-E$, Activity of a differential conditioned stimulus-related neuron during the reward task. $A$, Response to Tone 1 predicting sucrose solution $(S u c) ; B$, response to Tone $1+$ Light 1 predicting no reinforcement; $C$, response to Light 1 predicting sucrose solution; $D$, response to Tone $2+$ Light 2 predicting sucrose solution; $E$, response to Light 2 predicting no reinforcement. Note that the neuron responded to Tone 1, Light 1, Tone $2+$ Light 2, and ingestion of sucrose solution, but not to Tone $1+$ Light 1 or to Light 2. F, Activity of a differential conditioned stimulusrelated neuron during spontaneous movements of the tongue during intertrial interval. Note that activity of the neuron increased regardless of EMG activity in $A, C$, and $D$ and that EMG activity increased regardless of the neuronal activity in $F$. Other descriptions as for Figure 2.

\section{Differential conditioned stimulus-related neurons}

Of the 109 conditioned stimulus-related neurons, 97 responded differentially only to the conditioned sensory stimuli associated with reinforcement (differential neurons), but not to the conditioned sensory stimuli not associated with reinforcement. Of these 97, 12 differential conditioned stimulus-related neurons were tested further with the avoidance task. Of these 12 neurons, 10 neurons did not respond to the auditory stimulus (Tone 4) predicting electric shock. The remaining two neurons responded similarly to both conditioned stimuli predicting reward and aversion, but not to neutral stimuli not associated with reward or aversion.
Of these 97 differential conditioned stimulus-related neurons, most $(92.8 \%, 90 / 97)$ were multimodal neurons that responded to both visual and auditory conditioned stimuli associated with reward as well as ingestion of sucrose solution. A typical example of a multimodal differential neuron is shown in Figures 5 and 6 . The neuron, which was the same neuron shown in Figures 3 and 4, responded to various conditioned sensory stimuli predicting reward. In the reward task using the auditory conditioned stimuli, the neuron responded to Tone 1 predicting sucrose solution as well as ingestion of sucrose solution (Fig. $5 A$ ) and to Tone 3 predicting ICSS (Fig. $5 B$ ), but not to Tone 2 predicting no reward (Fig. $5 C$ ). In the reward task using the visual conditioned stimuli, 


\section{A EMG-triggered}

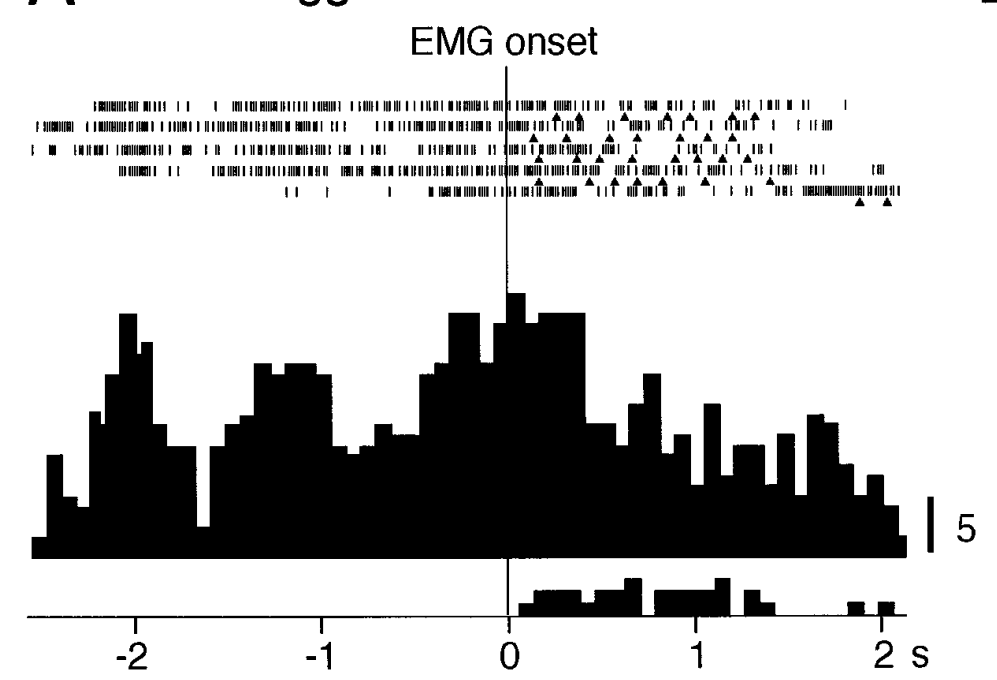

\section{B Neuronal activities before and after EMG onset}

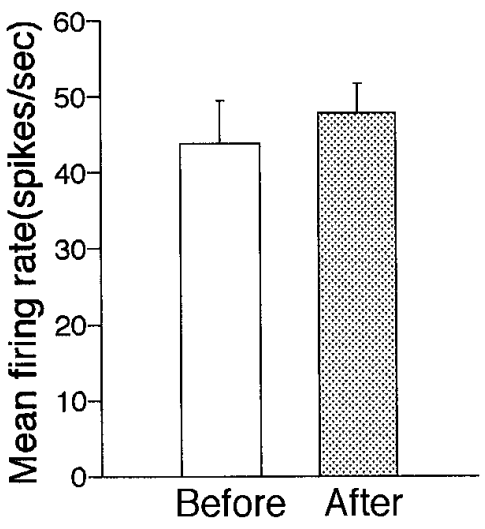

Figure 4. Activity of the conditioned stimulus-related neuron shown in Figure 3. A, Raster displays and accumulated histogram of the discharges of the conditioned stimulus-related neuron during the reward task. Raster displays and the histogram were aligned with the EMG onset. Other descriptions as for Figure $2 C$. B, Histogram of the mean firing rates for $800 \mathrm{msec}$ before and after the genioglossus EMG onset. Note no significant difference in neuronal activity before and after onset of the genioglossus EMG activity (paired $t$ test, $p>0.05$ ). Other descriptions as for Figure $2 D$.

the neuron responded to Light 1 predicting sucrose solution as well as ingestion of sucrose solution (Fig. $6 \mathrm{Aa}$ ), but not to Light 2 predicting no reward (Fig. $6 A b$ ). The neuron also differentially discriminated the configural stimuli based on the reward contingency. The neuron responded to Tone $2+$ Light 2 , associated with sucrose solution, even though each stimulus predicted no reinforcement when presented separately (Fig. $6 B a$ ). Conversely, the neuron did not respond to Tone $1+$ Light 1 , associated with no reinforcement, even though each stimulus predicted sucrose solution when presented separately (Fig. 6Bb).

The remaining seven neurons responded only to conditioned auditory $(n=5)$ or visual $(n=2)$ stimuli (unimodal differential conditioned stimulus-related neurons). These neurons responded to the conditioned sensory stimuli associated with reward if the stimuli included auditory (auditory differential conditioned stimulus-related neurons) or visual (visual differential conditioned stimulus-related neurons) stimuli, regardless of elemental and configural stimuli. The firing pattern of a typical example of a unimodal (auditory) differential neuron is shown in Figure 7 as raster displays and accumulated histograms during the reward task. This neuron responded to Tone 1 predicting sucrose solution $(A a)$, Tone 3 predicting ICSS $(A b)$, and Tone $2+$ Light 2 predicting sucrose solution $(\mathrm{Ca})$, but not to Tone 2 predicting no reinforcement $(A c)$ or Tone 4 predicting electric shock $(A d)$. On the other hand, the neuron did not respond to the conditioned visual stimuli associated with and without reinforcement $(B a, b)$ or to configural stimuli (Tone 1+Light 1 ) predicting no reinforcement $(\mathrm{Cb})$. The neuron seemed to respond to ingestion of sucrose in $A a$; however, the neuron did not respond to ingestion of sucrose in $B a$. Therefore, the neuronal responses during the ingestion period in $A a$ were not attributed to ingestion of sucrose per se, but to continuing responses after activity by Tone 1 . Similarly, neuronal responses to ICSS in $A b$ were not attributed to responses to ICSS per se, because incidental application of ICSS did not evoke significant neuronal responses (not shown). Thus, this neuron responded only to conditioned auditory stimuli predicting reward.

\section{Nondifferential conditioned stimulus-related neurons}

These 12 neurons responded nondifferentially to any conditioned stimuli. A typical example of a nondifferential neuron is shown in Figure 8 as raster displays and histograms during the reward and avoidance tasks. The neuron responded to all conditioned stimuli regardless of reward contingency $(A-C)$ and to ingestion of sucrose $(A a, B a, C a)$. Furthermore, this neuron responded to any sensory stimulus in the environment, such as human voices, movements of the experimenter, opening and closing of the door of the experimental room, etc. (not shown). The other 11 nondifferential neurons also responded nondifferentially to conditioned and unconditioned stimuli as well as to various uncontrolled sensory stimuli.

\section{Effects of extinction and relearning on neuronal responses to conditioned stimuli}

Fifty neurons (conditioned stimulus related, 43; conditioned behavior related, 7) were tested during extinction in which rewards were no longer given. Response levels to conditioned stimuli of all 50 neurons significantly decreased during the course of extinction. The 46 neurons (conditioned stimulus related, 39; conditioned behavior related, 7) were tested further with relearning trials in which rewards were now reinstated. Of these 46 neurons, response levels to the conditioned stimulus of 44 neurons (conditioned stimulus related, 37; conditioned behavior related, 7) increased along with a return of behavioral response. These results suggest that responses of MD neurons to conditioned sensory stimuli was linked associatively to the stimulus-reward contingency.

A typical example of plastic changes in neuronal and behavioral responses during extinction and relearning trials is shown in Figure 9. Figure $9 A$ shows a raster display of neuronal discharges and lick signals during extinction and relearning trials of the same neuron shown in Figures 3-6. In preextinction (Control) trials, the neuron was activated by both Tone 1 predicting sucrose solution and ingestion of sucrose solution. In extinction trials (Extinction), the neuronal activation by Tone 1 gradually decreased and finally 


\section{Auditory stimuli}
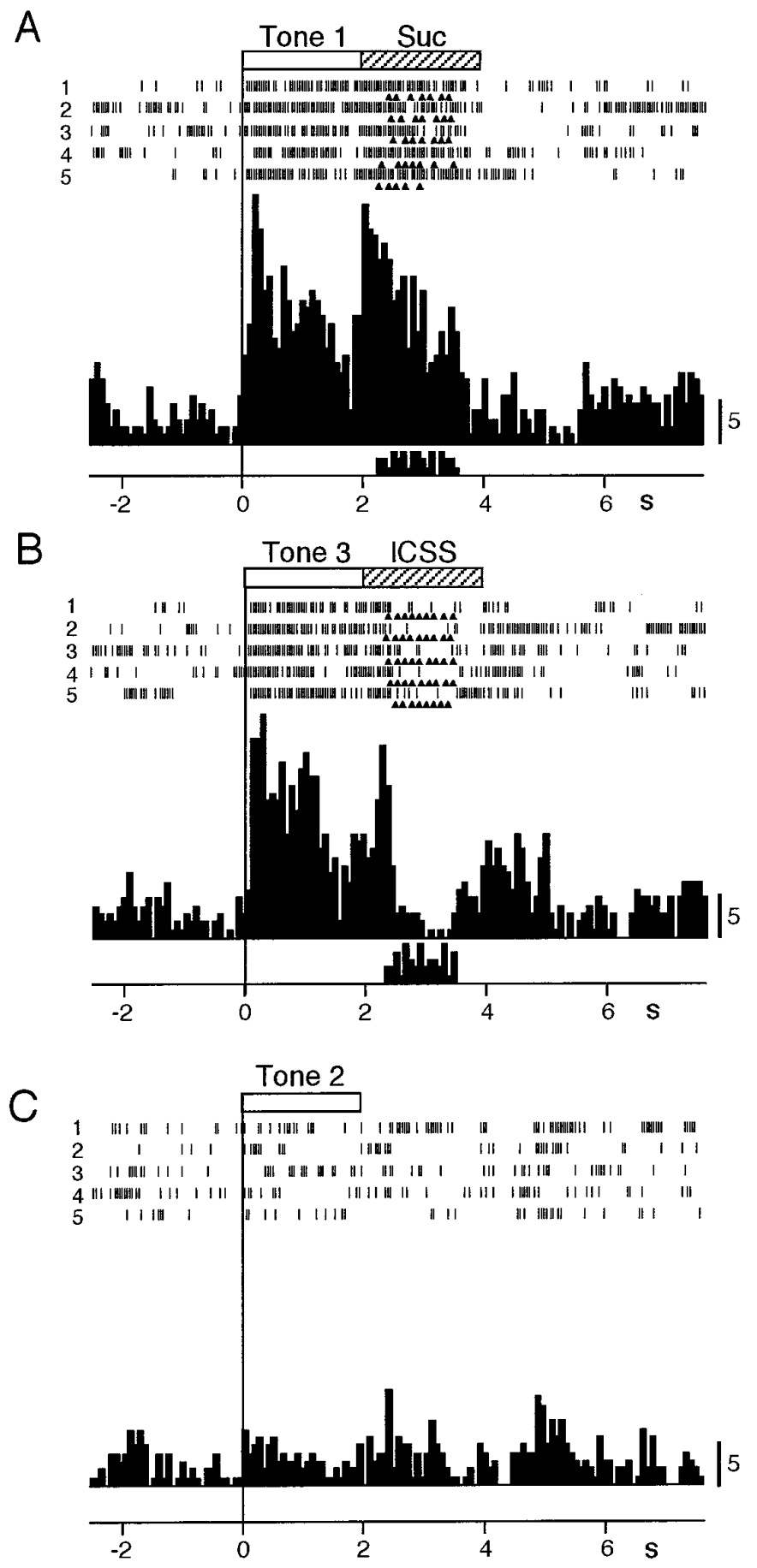

Figure 5. Activity of the multimodal differential conditioned stimulusrelated neuron shown in Figure 3 during the reward task using auditory conditioned stimuli. $A-C$, Raster displays and histograms of neuronal responses to Tone 1 predicting sucrose solution $(S u c)(A)$, Tone 3 predicting $\operatorname{ICSS}(B)$, and Tone 2 predicting no reinforcement $(C)$. Note that the neuron responded to Tone 1, Tone 3, and ingestion of sucrose solution, but not to Tone 2. Open and hatched rectangles at top indicate duration of conditioned stimulus and time of reinforcement, respectively. Each triangle below a raster line indicates one lick; top histograms show accumulated neuronal responses, and bottom histograms show accumulated licks. Time scale in seconds; 0 in time scale indicates onset of a conditioned stimulus; minus is pretrial control; each histogram bin, $80 \mathrm{msec}$. disappeared. Behavioral responses (licking) also gradually decreased and disappeared on the fourth trial. In the first relearning trial (Relearning, trial 21), the neuron was not activated by Tone 1 , although the rat licked a spout. On the second trial of relearning (trial 22), the neuron was activated by both Tone 1 and ingestion of sucrose solution. From the 3rd (trial 23) to the 35th (trial 35) relearning trials, the neuronal activation by Tone 1 gradually resumed. The changes in neuronal activation by Tone 1 during control, extinction, and relearning trials are shown quantitatively in Figure $9 B, a$ and $b$. The ordinate of Figure $9 B a$ indicates response magnitude to Tone 1 in each trial, which is defined as the mean firing rate during presentation of Tone 1 minus mean spontaneous firing rate. Neuronal activation (response magnitude) gradually decreased over the course of extinction in trials 6-14 and became the level close to the spontaneous firing rate in trials 15-20. In relearning trials, neuronal activation gradually increased in trials $21-29$, and in trials $31-35$, it resumed to a level comparable to that during control trials in trials $1-5$. The mean response magnitude during each block of five trials is shown in Figure $9 \mathrm{Bb}$. Mean response magnitudes in blocks 3 and 4 during extinction trials were significantly smaller than that in block 1 (control) (Tukey test after one-way ANOVA, $p<0.05$ ). Mean response magnitudes in blocks 6 and 7 were not significantly different from that in block 1 (Tukey test after one-way ANOVA, $p>0.05)$

\section{Neuronal responses during the reward task with delay}

The 14 multimodal differential conditioned stimulus-related neurons were tested with the reward task with delay. Of these, 8 $(57.1 \%, 8 / 14)$ responded during the delay period as well as during the conditioned sensory stimulation and ingestion periods. A typical example of a multimodal differential conditioned stimulusrelated neuron that responded during the delay period is shown in Figure 10. In the reward task without delay, the neuron responded to Tone 1 predicting sucrose solution and ingestion of sucrose solution $(A)$. In the reward task with delay, the neuron responded during the delay period as well as during the conditioned auditory stimulation and ingestion period $(B)$. Two examples of EMG activity during the reward task with and without delay are shown below the histograms. The neuronal discharges were time-locked to Tone 1 during the conditioned sensory stimulation period and were not correlated to EMG activity during the delay period, because the increase in neuronal activity continued during the delay period without an increase in EMG activity. These results suggest that the neuronal responses during the delay period were not preparatory responses for licking but were related to shortterm memory of the conditioned sensory stimulus.

\section{Response latency of the MD neurons to conditioned sensory stimuli}

Because there were no differences in response latencies of the conditioned stimulus-related neurons between elemental (auditory and visual) and configural stimuli (Tukey test after one-way ANOVA, $p>0.05$ ), only those to elemental stimuli were analyzed. Response latencies of the conditioned stimulus-related neurons to conditioned auditory and visual stimuli are shown in Figure 11. Response latencies of unimodal differential neurons to auditory stimuli ranged from 90 to $1400 \mathrm{msec}(402.0 \pm 251.1$, mean \pm SEM; $n=5)$, and those to visual stimuli were 170 and 800 msec $(485.0 ; n=2)(A)$. Response latencies of multimodal differential neurons to auditory stimuli ranged from 50 to $1550 \mathrm{msec}$ $(400.1 \pm 37.5 ; n=90)$, and those to visual stimuli ranged from 60 


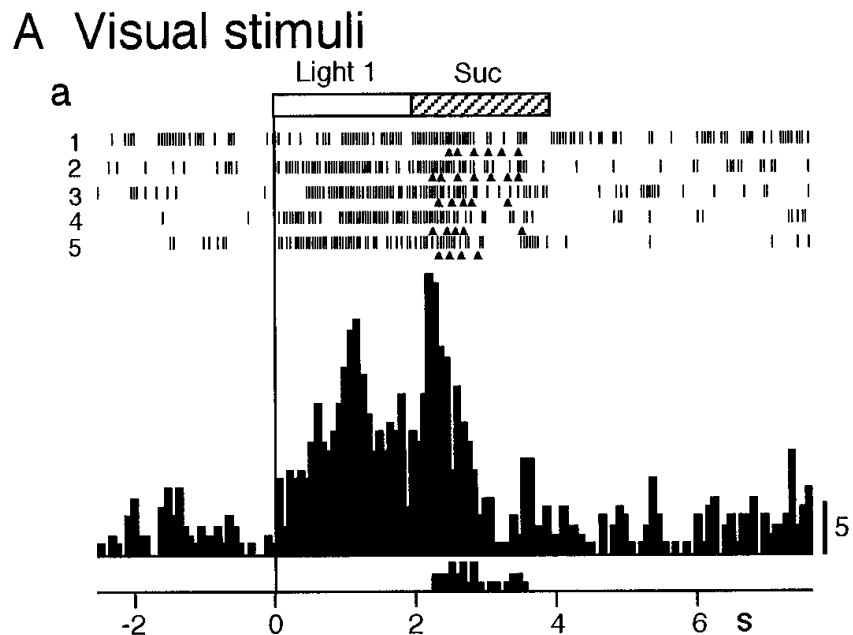

\section{B Configural stimuli}
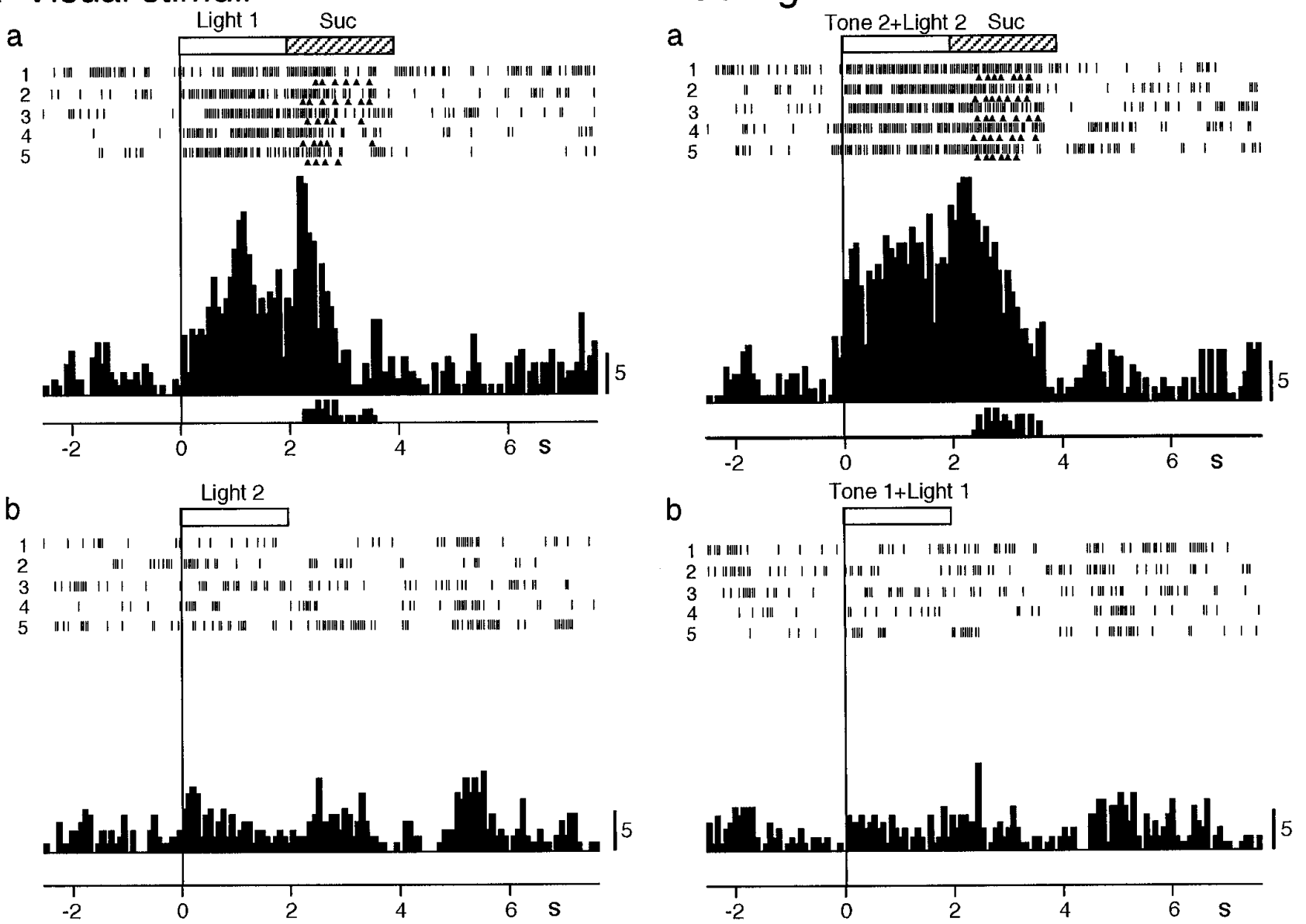

Figure 6. Activity of the multimodal differential conditioned stimulus-related neuron shown in Figure 3 during the reward task using visual and configural conditioned stimuli. $A$, B, Raster displays and histograms of neuronal responses to Light 1 predicting sucrose solution (Suc) (Aa), Light 2 predicting no reinforcement $(A b)$, Tone $2+$ Light 2 predicting sucrose solution $(B a)$, and Tone $1+$ Light 1 predicting no reinforcement $(B b)$. Note that the neuron responded to Light 1, Tone 2+Light 2, and ingestion of sucrose solution, but not to Light 2 and Tone 1+Light 1. Other descriptions as for Figure 5 .

to $1850 \mathrm{msec}(421.8 \pm 46.7 ; n=77)$ (top histograms in Ba,b). Response latencies of nondifferential neurons to auditory stimuli ranged from 34 to $79 \mathrm{msec}(56.7 \pm 4.4 ; n=12)$, and those to visual stimuli ranged from 30 to $70 \mathrm{msec}(50.5 \pm 3.8 ; n=12)$ (bottom histograms in $B a, b)$.

There were significant differences in neuronal response latencies to conditioned auditory and visual stimuli of the differential and nondifferential conditioned stimulus-related neurons (oneway ANOVA; $\left.F_{(3,187)}=6.981 ; p<0.01\right)$. Response latencies of multimodal differential conditioned stimulus-related neurons to conditioned auditory stimuli were significantly longer than those of nondifferential conditioned stimulus-related neurons (Tukey test, $p<0.05$ ) and those of multimodal differential conditioned stimulus-related neurons to conditioned visual stimuli were significantly longer than those of nondifferential conditioned stimulus-related neurons (Tukey test, $p<0.05$ ).

The response latencies of the multimodal differential conditioned stimulus-related neurons had a bimodal distribution. One had response latencies $<300 \mathrm{msec}$, with a peak latency of 100-125 msec; the others had response latencies $>300 \mathrm{msec}$, with a peak latency of $500-600 \mathrm{msec}$.

\section{Spontaneous firing rate}

The spontaneous firing rates of differential conditioned stimulusrelated neurons ranged from 1.1 to $20.9(n=95)$ spikes/sec; those of nondifferential conditioned stimulus-related neurons ranged from 2.9 to $40.0(n=12)$ spikes/sec; those of conditioned behavior-related neurons ranged from 1.6 to $14.4(n=13)$ spikes/ sec; and those of nonresponsive neurons ranged from 1.7 to 21.3 $(n=39)$ spikes/sec. The mean spontaneous firing rates of differential conditioned stimulus-related, nondifferential conditioned stimulus-related, conditioned behavior-related, and nonresponsive neurons are shown in Figure 12. There were significant differences in the mean spontaneous firing rate among the four types of neurons (one-way ANOVA; $F_{(3,155)}=2.88 ; p<0.05$ ). The spontaneous firing rate of nondifferential neurons was significantly higher than those of the others (Tukey test, $p<0.05$ ).

\section{Distributions of recording sites of the MD neurons}

The recording sites of all recorded MD neurons are shown in Figure 13. Neuronal activity was recorded evenly from all segments of the MD; however, the responsive neurons (all excited, open circles) tended to be located more densely in the rostral part of the MD.

The distributions of each type of responsive neurons are shown in Figure 14. The conditioned behavior-related neurons (open triangles) were located in the MDL. The nondifferential conditioned stimulus-related neurons (open square) were located evenly throughout the MD. Because the total number of unimodal differential neurons was relatively small, unimodal differential con- 
A Auditory stimuli
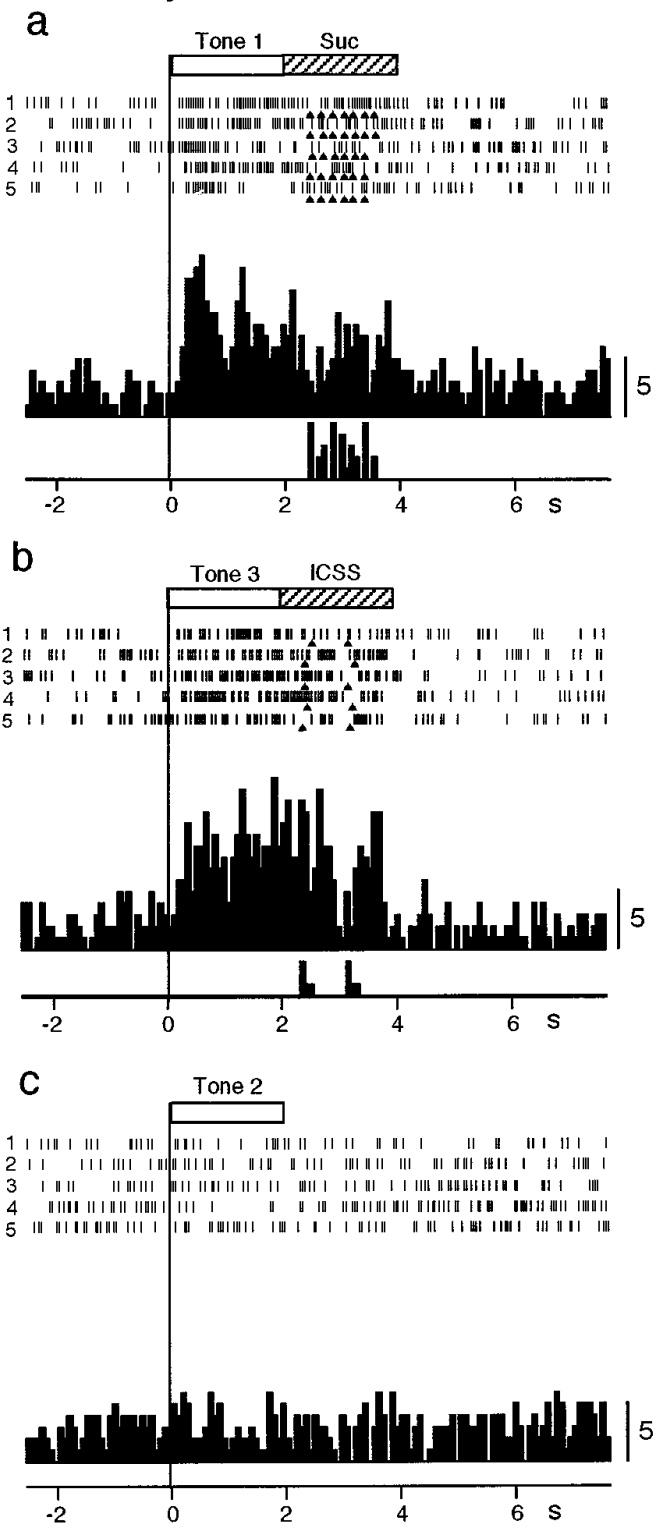

d

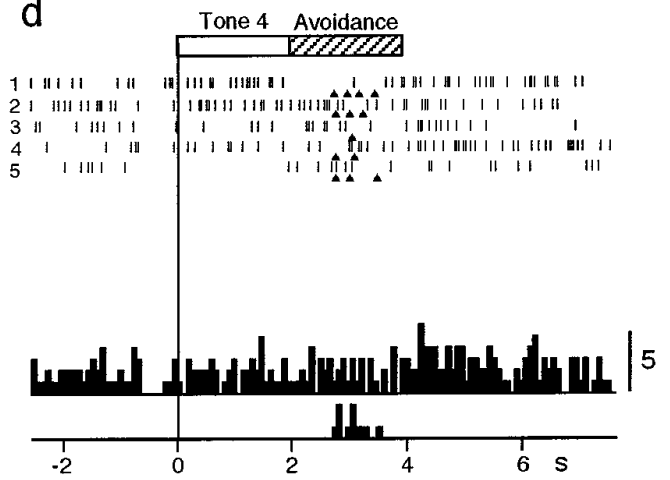

B Visual stimuli
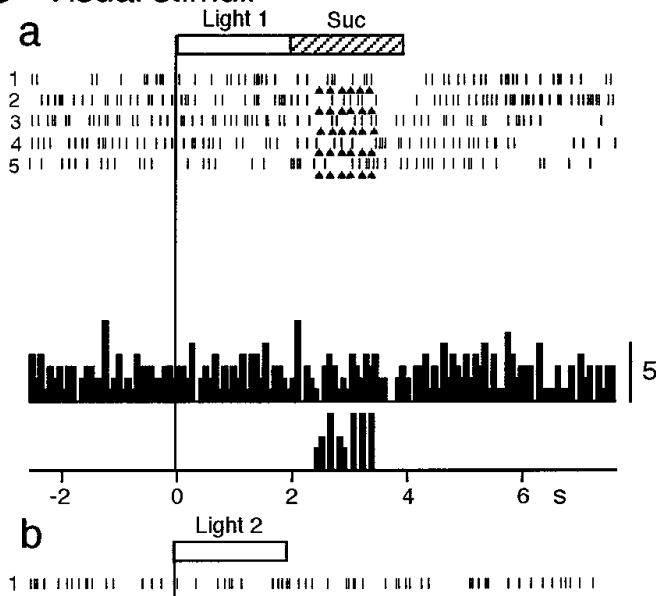

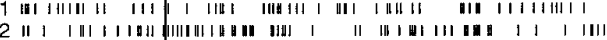

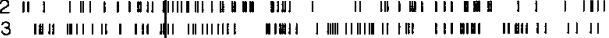
3 4 (11)

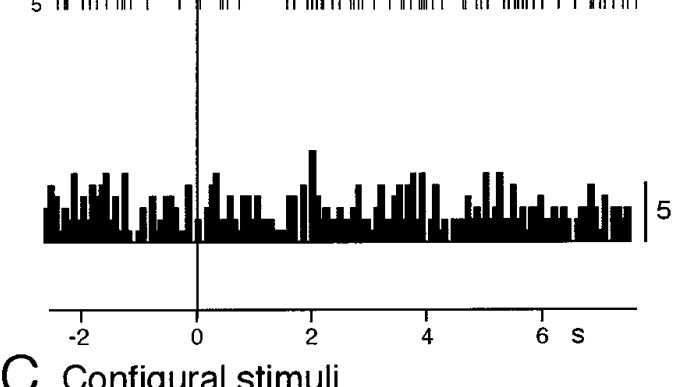

C Configural stimuli

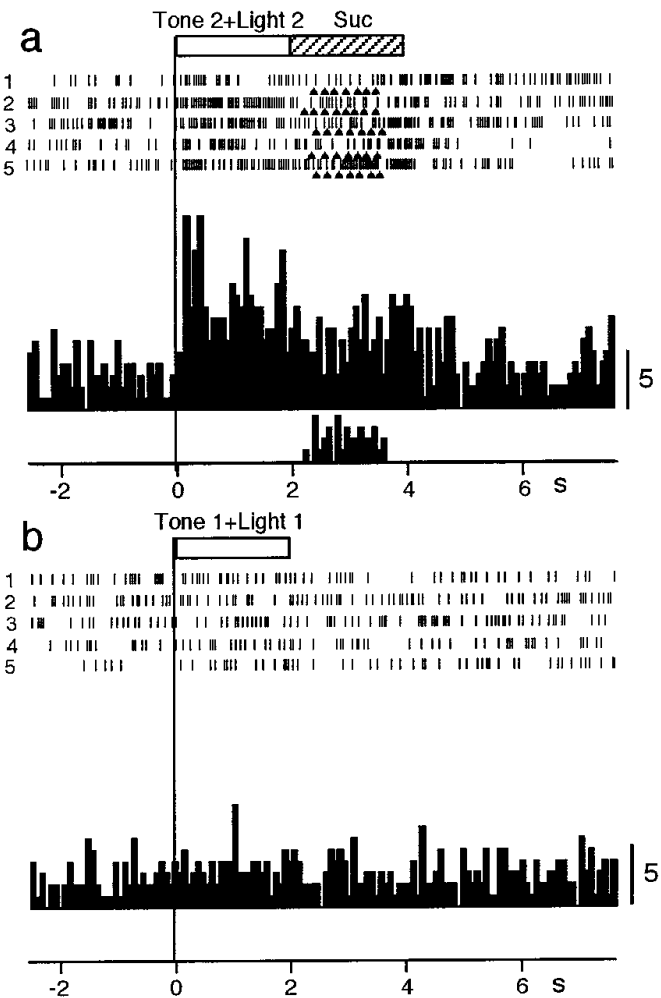

Figure 7. Activity of a differential conditioned stimulus-related neuron that responded to unimodal (auditory) stimuli. $A-C$, Raster displays and histograms of neuronal responses to Tone 1 predicting sucrose solution $(S u c)(A a)$, Tone 3 predicting ICSS $(A b)$, Tone 2 predicting no reinforcement $(A c)$, Tone 4 predicting electric shock $(A d)$, Light 1 predicting sucrose solution $(B a)$, Light 2 predicting no reinforcement $(B b)$, Tone $2+$ Light 2 predicting sucrose solution $(C a)$, Tone $1+$ Light 1 predicting no reinforcement $(C b)$. Note that the neuron responded to conditioned stimuli predicting reward only if the conditioned stimuli included auditory stimulus (i.e., Tone 1, Tone 3, and Tone 2+Light 2) and that the neuron did not respond to the conditioned visual stimulus predicting reward (Light 1) or other stimuli predicting no reward (Tone 2, Tone 4, Light 2, Tone 1+Light 1). Other descriptions as for Figure 5. 
A Auditory stimuli
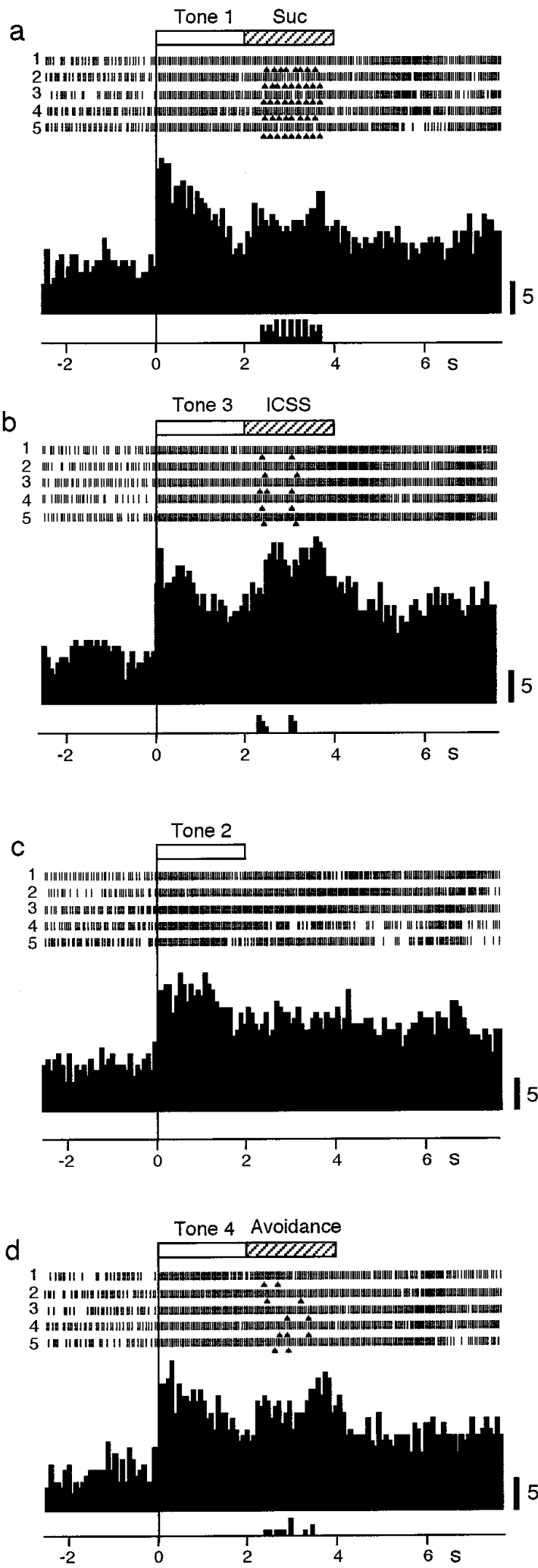

B Visual stimuli
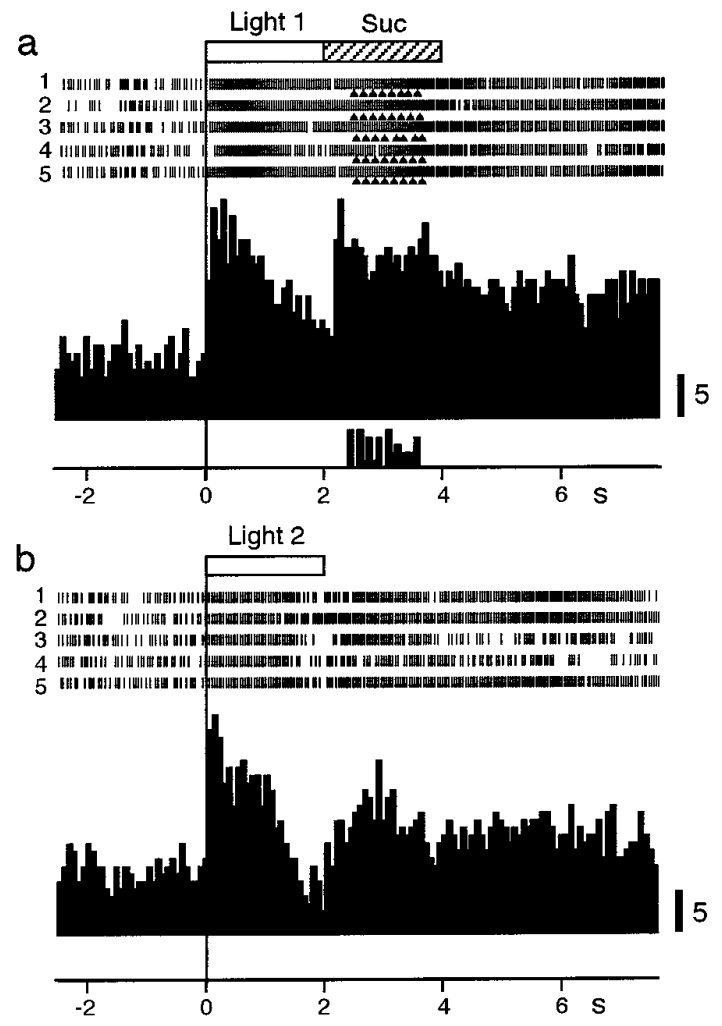

C Configural stimuli

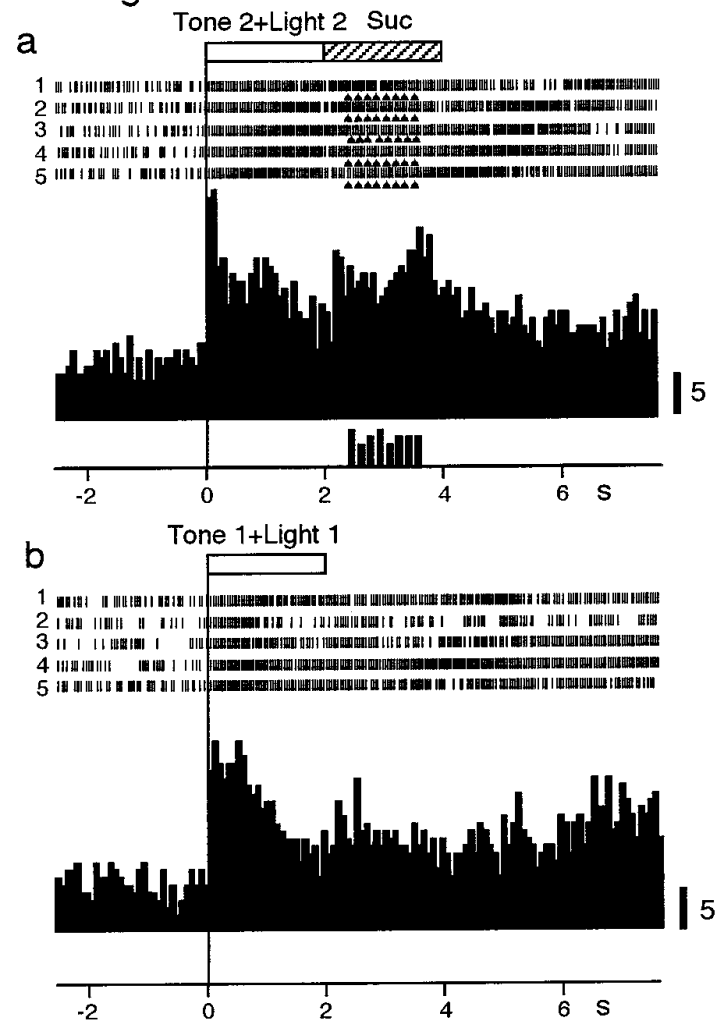

Figure 8. Activity of a nondifferential conditioned stimulus-related neuron that responded indiscriminately to all conditioned sensory stimuli. $A-C$, Raster displays and histograms of neuronal responses to Tone 1 predicting sucrose solution (Suc) (Aa), Tone 3 predicting ICSS (Ab), Tone 2 predicting no reinforcement $(A c)$, Tone 4 predicting electric shock $(A d)$, Light 1 predicting sucrose solution $(B a)$, Light 2 predicting no reinforcement $(B b)$, Tone $2+$ Light 2 predicting sucrose solution $(\mathrm{Ca})$, Tone $1+$ Light 1 predicting no reinforcement $(\mathrm{Cb})$. Note that the neuron responded to all conditioned sensory stimuli. Other descriptions as for Figure 5. 

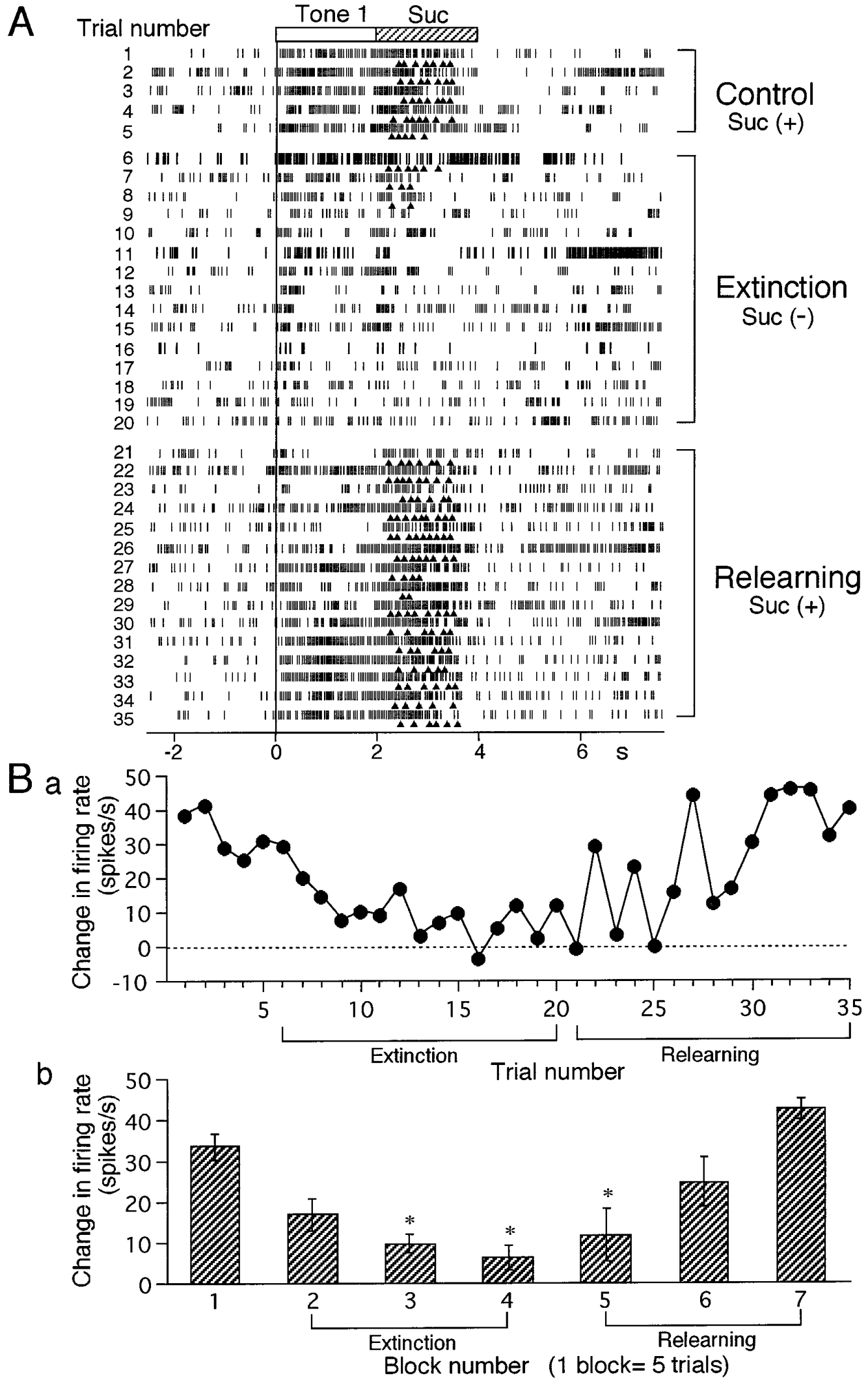

Figure 9. Activity of the differential conditioned stimulus-related neuron shown in Figure 3 during extinction and relearning trials. $A$, Raster displays of the neuronal discharges during control, extinction, and relearning trials. Trials 1-5, control trials before extinction; trials 6-20, extinction trials; trial 21-35, relearning trials. $B$, Response magnitude to the conditioned stimulus in each trial $(a)$ and in each block consisting of five trials $(b)$. Response magnitude was defined as the mean firing rate during conditioned sensory stimulation period minus the mean spontaneous firing rate. In $B b$, the blocks with asterisks show that the response magnitudes were significantly smaller than that of the control before extinction (Tukey test after one-way ANOVA, $p<0.05$ ). Other descriptions as for Figure 5. 


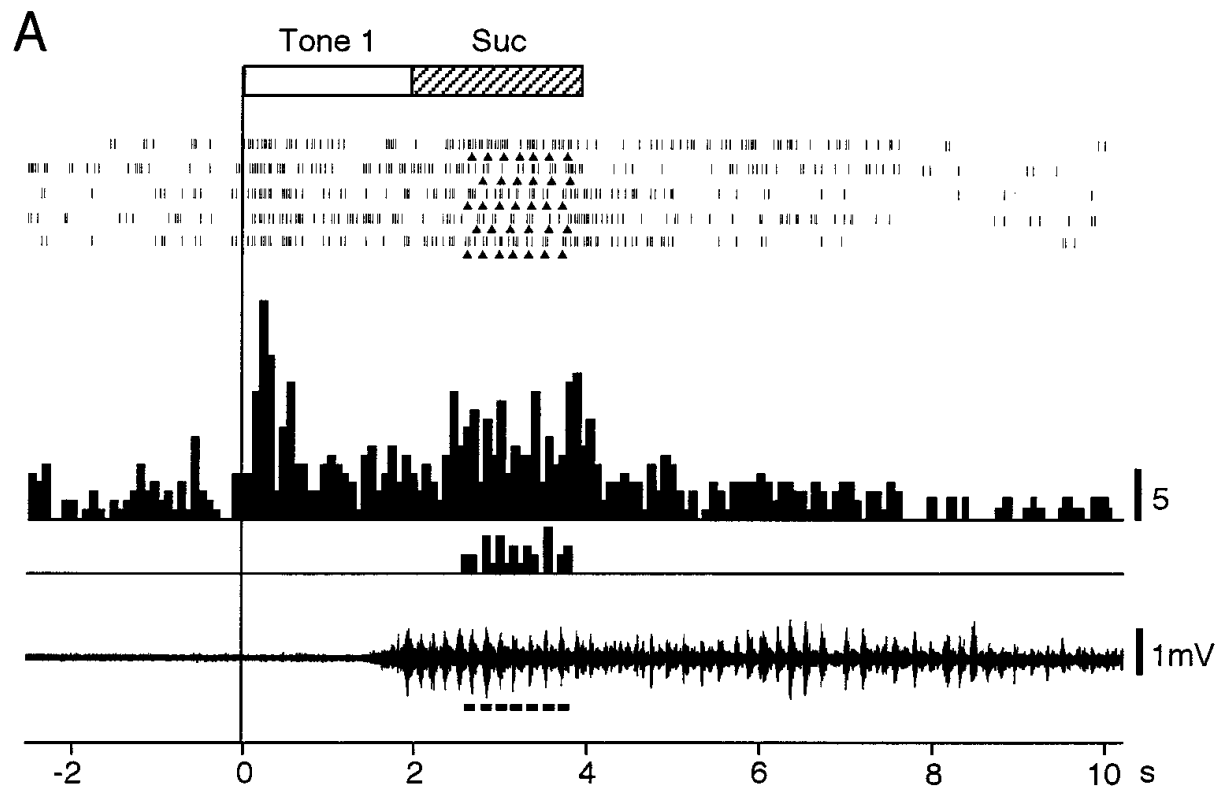

Figure 10. Activity of a differential conditioned stimulus-related neuron that responded during a delay time in the reward task with delay. $A, B$, Raster displays and histograms of neuronal responses and the raw records of the genioglossus EMG activity in the reward task without delay $(A)$ and with delay $(B)$. In the reward task with delay, the neuron responded during the delay period $(2.4 \mathrm{sec})$, whereas no EMG activity was observed during the delay period. Other descriptions as for Figure 5.

B

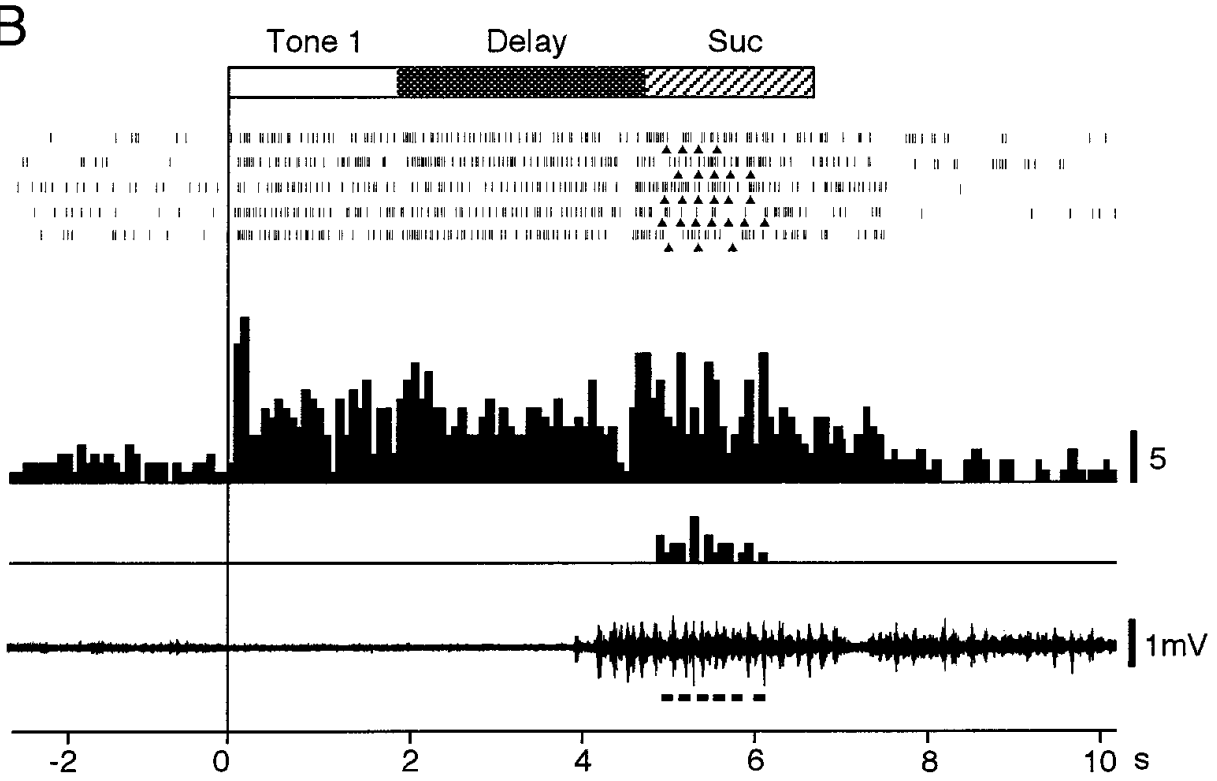

ditioned stimulus-related neurons were included with multimodal differential conditioned stimulus-related neurons and similarly grouped into two types: differential conditioned stimulus-related with response latencies of $<300 \mathrm{msec}$ (solid circles) and differential conditioned stimulus-related with response latencies $>300$ msec (open circles). The differential conditioned stimulus-related neurons with short response latencies (solid circles) were located mainly in the rostromedial segment of MD. The differential conditioned stimulus-related neurons with long response latencies (open circles) were located evenly throughout the MD. The differential neurons that responded during the delay period were located mainly in the medial segment of MD (not shown).

\section{DISCUSSION}

\section{Conditioned behavior-related neurons}

Activity of the conditioned behavior-related neurons increased before licking behaviors in the present study. Similar neuronal activity preceding motor events was reported in various motor systems such as the primary motor cortex (Lamarre et al., 1983), the premotor cortex (Kubota and Hamada, 1978; Kurata and Tanji, 1986), the supplementary motor area (Tanji and Kurata, 1982), the basal ganglia (Liles, 1985; Mitchell et al., 1987), and the cingulate cortex (Shima et al., 1991). It should be noted, however, that the activity of the conditioned behavior-related neurons was not correlated to licking behaviors during the intertrial interval in the present study. Furthermore, the activity of all conditioned behavior-related neurons that were tested changed during extinction and relearning trials. These results suggest that the conditioned behavior-related neurons were not involved in simple motor functions but were involved in motor learning related to stimulus-response associations during the task.

In the present study, the conditioned behavior-related neurons were located mainly in the MDL. Anatomical studies suggest that the MDL is one of the components of the limbic motor circuit 

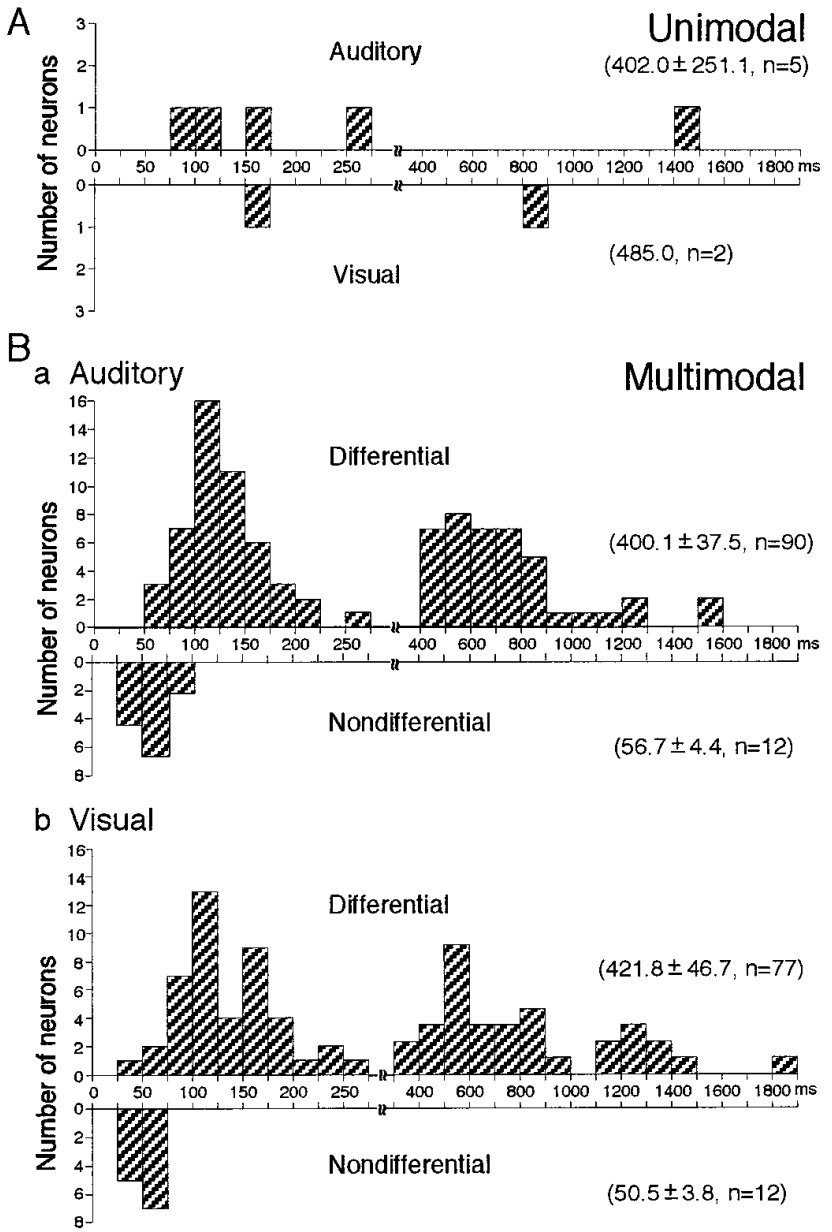

Figure 11. Frequency histograms of neuronal response latencies to conditioned sensory stimuli. $A$, Distributions of neuronal response latencies of unimodal differential conditioned stimulus-related neurons. Top and bottom histograms show the latencies of auditory and visual responsive neurons, respectively. $B$, Distributions of neuronal response latencies of multimodal differential (top histogram) and nondifferential (bottom histogram) conditioned stimulus-related neurons to auditory $(a)$ and visual $(b)$ conditioned stimuli. Mean latencies of differential conditioned stimulusrelated neurons to auditory and visual stimuli were significantly longer than those of nondifferential conditioned stimulus-related neurons (Tukey test after one-way ANOVA, $p<0.05$ ).

(dorsal anterior cingulate circuit), which includes the MDL, the dorsal anterior cingulate cortex, the dorsomedial striatum, and the medial portion of the globus pallidus (Groenewegen et al., 1990). Task-related neuronal activity preceding motor events, comparable to that of the conditioned behavior-related neurons in the present study, has been reported in the anterior cingulate cortex in monkeys during key press movements (Shima et al., 1991) and in the caudate nucleus in monkeys during sensory- or memory-guided saccade tasks (Hikosaka et al., 1989). Interestingly, saccade-related neuronal responses in the monkey caudate, which receives afferent inputs from the MDL via the anterior cingulate cortex, were not evident during spontaneous eye movements (Hikosaka et al., 1989). The MDL also receives afferents from other motor-related areas such as the reticular part of the substantia nigra (Groenewegen, 1988; Kuroda and Price, 1991b), where neurons also showed activity preceding a saccade (Hikosaka and Wurtz, 1983). Taken together, neurons in each area of the dorsal anterior cingulate circuit have similar characteristics

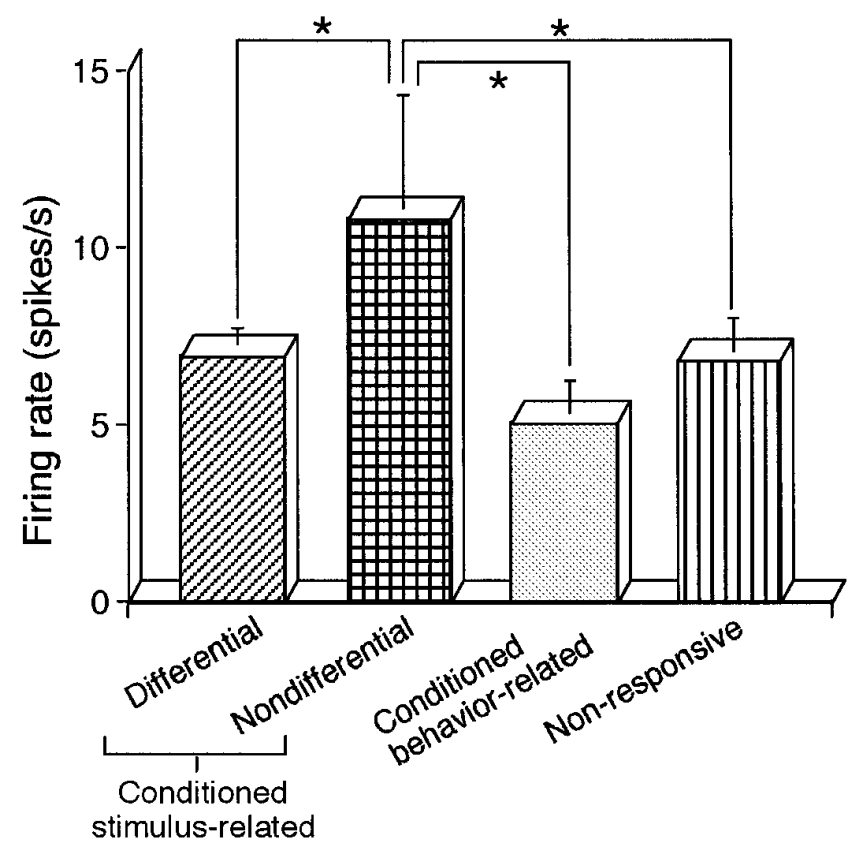

Figure 12. Histograms of mean spontaneous firing rates of differential conditioned stimulus-related, nondifferential conditioned stimulusrelated, conditioned behavior-related, and nonresponsive neurons. Asterisks indicate the mean spontaneous firing rates of the nondifferential conditioned stimulus-related neurons, which were significantly higher than those of the others (Tukey test after one-way ANOVA, $p<0.05$ ).

with respect to motor events. This similarity of the neuronal characteristics strongly supports the existence of a motor circuit in the limbic system.

\section{Differential conditioned stimulus-related neurons}

The most responsive MD neurons in the present study were differential conditioned stimulus-related neurons (79.5\%), the activity of which was not correlated with behavioral responses during the task or during the intertrial interval. Most differential neurons $(92.8 \%)$ were multimodal neurons responding to both conditioned auditory and visual stimuli predicting reward. Furthermore, most differential neurons $(83.3 \%)$ responded only to the conditioned stimuli predicting reward but not to the conditioned stimulus predicting electric shock. These differential responses to the conditioned stimuli were not just sensory responses. First, these neurons responded differentially to simultaneous presentation (configural stimuli) of the conditioned auditory and visual stimuli associated with and without reward. In the configural situation, the reward contingency of the stimuli presented in compound was opposite that of the elemental stimuli presented alone, even though the exact same sensory stimuli were involved. This indicates that differential neuronal responses to the conditioned stimuli were attributable to the reward contingency predicted by the stimuli rather than to the physical properties of the stimuli. Second, most differential conditioned stimulus-related neurons $(94.9 \%)$ changed their response patterns during extinction and relearning trials, even though the same physical stimulus was presented repeatedly. These results suggest strongly that the differential conditioned stimulus-related neurons are involved in stimulus-reward associations, consistent with lesion studies in the monkey MD (Gaffan and Murray, 1990; Gaffan et al., 1993).

The differential conditioned stimulus-related neurons were located mainly in the rostral MD. Those with response latencies of 


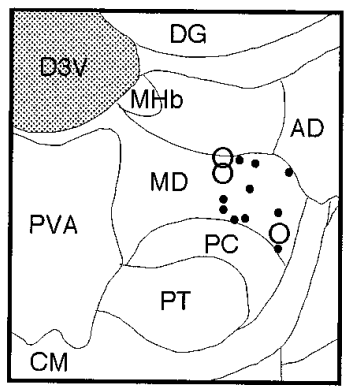

$-1.8$

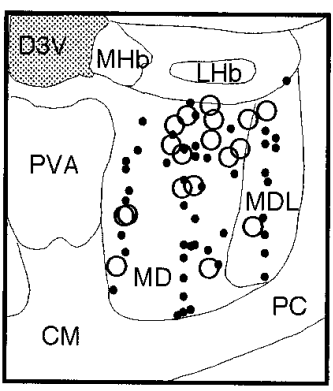

$-2.12$

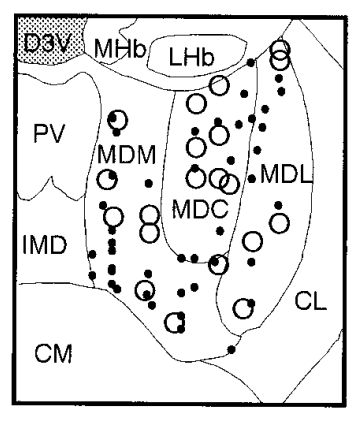

$-2.3$

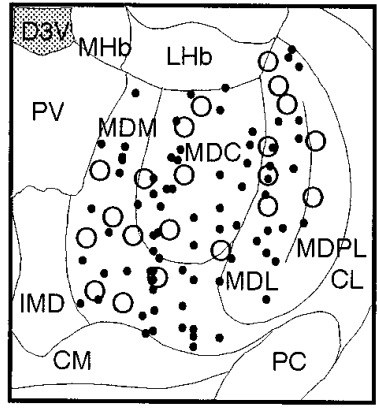

$-2.56$

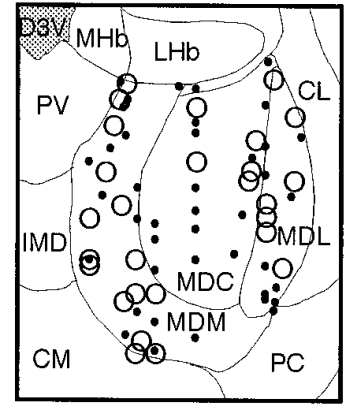

$-2.8$

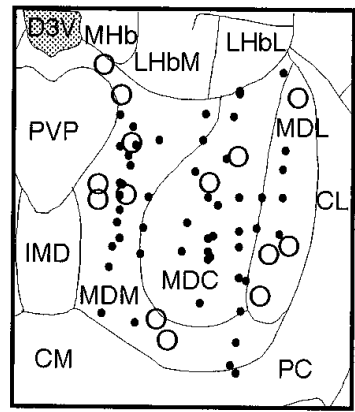

$-3.14$

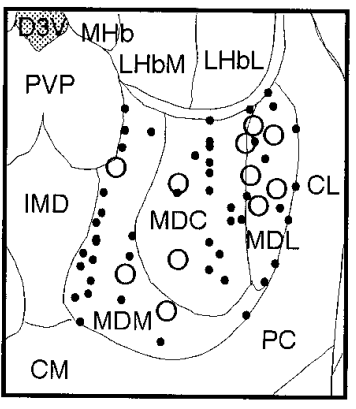

$-3.3$

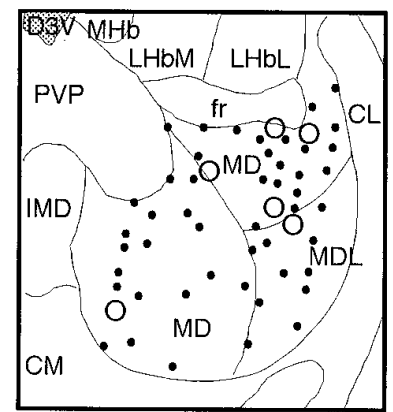

$-3.6$

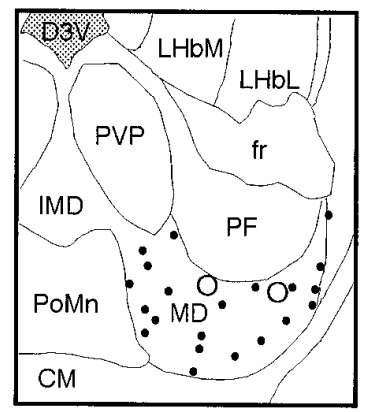

$-3.8$

Responsive (all excited) Non-responsive

Figure 13. Locations of the recording sites in the rat MD. Frontal sections, based on the atlas of Paxinos and Watson (1986), are arranged rostrocaudally from left to right. Each value below each section indicates distance $(\mathrm{mm})$ posterior from the bregma. Open circles, Responsive neurons; dots, nonresponsive neurons. $A D$, Anterodorsal thalamic nucleus; $C M$, central medial thalamic nucleus; $C L$, centrolateral thalamic nucleus; $D 3 V$, dorsal third ventricle; $D G$, dentate gyrus; $f r$, fasciculus retroflexus; $I M D$, intermediodorsal thalamic nucleus; $L H b$, lateral habenular nucleus; $L H b L$, lateral habenular nucleus, lateral; $L H b M$, lateral habenular nucleus, medial; $M D$, mediodorsal thalamic nucleus; $M D C$, central segment of mediodorsal thalamic nucleus; $M D L$, lateral segment of mediodorsal thalamic nucleus; $M D M$, medial segment of mediodorsal thalamic nucleus; $M D P L$, paralaminar segment of mediodorsal thalamic nucleus; $M H b$, medial habenular nucleus; $P C$, paracentral thalamic nucleus; $P F$, parafascicular thalamic nucleus; $P T$, paratenial thalamic nucleus; $P V$, paraventricular thalamic nucleus; $P V A$, paraventricular thalamic nucleus, anterior; $P V P$, paraventricular thalamic nucleus, posterior; PoMn, posteromedian thalamic nucleus.

$<300$ msec were especially localized in the rostral MDM. Anatomical studies indicate that the basolateral nucleus of the amygdala projects to the (rostral) MDM (Russchen et al., 1987; Groenewegen, 1988; Kuroda and Price, 1991a,b; Ray and Price, 1992). In the rat amygdala, the response latencies of the basolateral neurons to conditioned auditory stimuli ranged from 45 to $115 \mathrm{msec}$, with a modal value of $90 \mathrm{msec}$ (Uwano et al., 1995). The auditory response latencies of the differential conditioned stimulus-related MD neurons with short response latencies ranged from 50 to $275 \mathrm{msec}$, with a modal value of $110 \mathrm{msec}$ in the present study. The mean response latency of the MD neurons was significantly longer than that of the basolateral amygdalar neurons (Student's $t$ test, $p<0.05$ ). This suggests that the MD neurons receive inputs from neurons in the basolateral nucleus of the amygdala. It has been reported that the amygdala has a pivotal role in stimulus-reinforcement association (Weiskrantz, 1956; Mishkin and Aggleton, 1981; Gaffan and Harrison, 1987; LeDoux, 1987; Davis, 1992, 1994). One of the areas within the amygdala responsible for learning stimulus-reinforcement was the basolateral nucleus of the amygdala (Everitt et al., 1989; Miserendino et al., 1990; Kim and McGaugh, 1992). Neurophysiological experiments reported that neurons in the basolateral nucleus of the rat and monkey amygdala responded differentially to multimodal conditioned sensory stimuli associated with reward (Nishijo et al., 1988a,b; Uwano et al., 1995). In the present study, the MD neurons also showed multimodal differential responses to conditioned sensory stimuli associated with reward. This similarity of the characteristics of the MD neurons to those of the basolateral amygdalar neurons also supports the idea that MD neurons receive inputs from the basolateral amygdalar neurons and suggest an intimate functional relationship between the amygdala and the MD.

\section{Delay-responsive differential conditioned stimulus-related neurons}

It has been reported that lesions of the MD produced deficits in the performance of various tasks with a delay time in rats and monkeys (Isseroff et al., 1982; Aggleton and Mishkin, 1983; ZolaMorgan and Squire, 1985; Stokes and Best, 1990; PeinadoManzano and Pozo-Garcia, 1991). In the present study, of the 14 differential conditioned stimulus-related neurons tested with the reward task with delay, $8(57.1 \%)$ responded during the delay period as well as during the conditioned sensory stimulation period predicting reward. In monkeys, unit recording studies also reported delay-responsive neurons in the MD during a delayed response task (Fuster and Alexander, 1973) as well as in the 


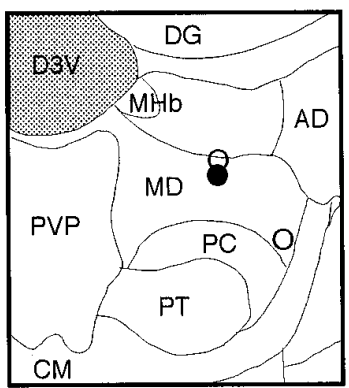

$-1.8$

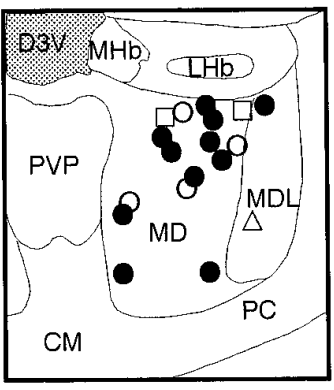

$-2.12$

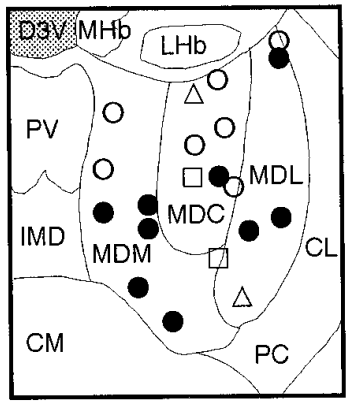

$-2.3$

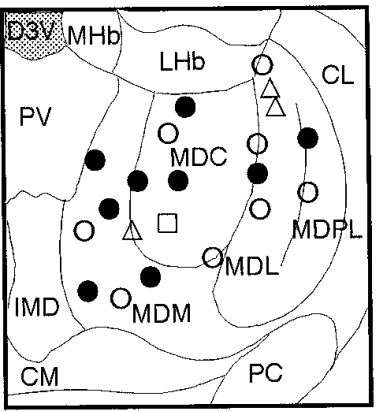

$-2.56$

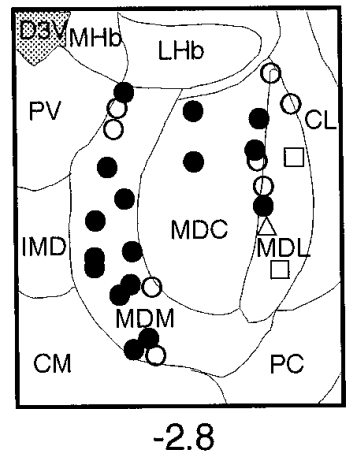

$-2.8$

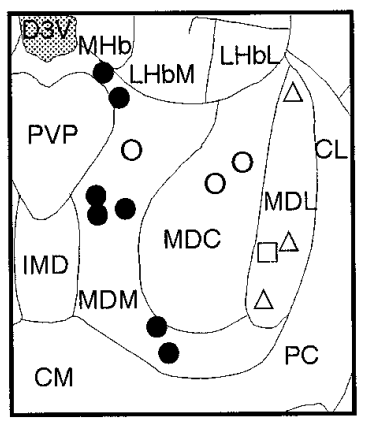

$-3.14$

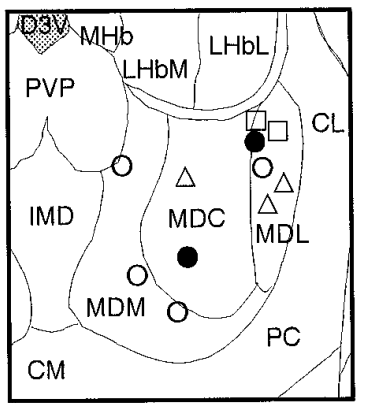

$-3.3$

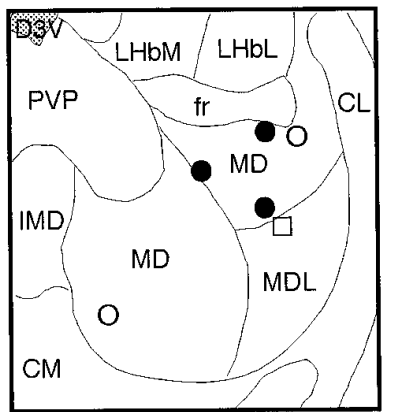

$-3.6$

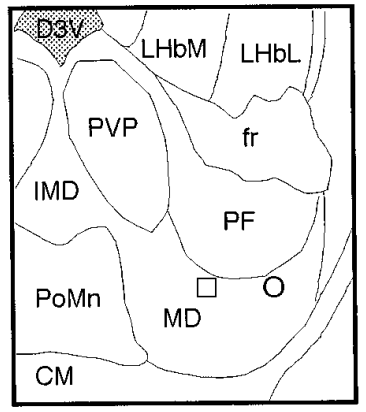

$-3.8$

\section{Conditioned behavior-related $\triangle$ \\ Conditioned stimulus-related Differential Short latency $(<300 \mathrm{~ms})$ Long latency $(\geqq 300 \mathrm{~ms})$ Nondifferential}

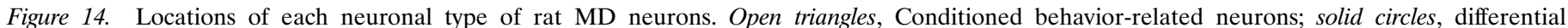

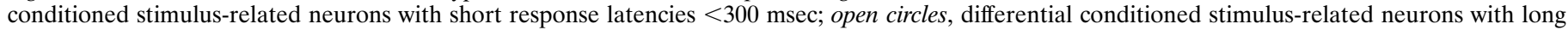
response latencies $>300 \mathrm{msec}$; open squares, nondifferential conditioned stimulus-related neurons. Other abbreviations as in Figure 13 .

prefrontal cortex, which has intimate anatomical connections with the MD (Funahashi et al., 1990, 1991). These results strongly suggest MD involvement in the short-term or working memory for reward.

\section{Role of the MD in configural learning and stimulus-significance decoding}

As described above, the MD neurons discriminated not only elemental but also configural stimuli. As far as we know, there have been no lesion and recording studies in the MD testing with configural discrimination. A previous lesion study reported that the amygdala might not be involved in processing compound stimuli (Falls and Davis, 1995). The hippocampal formation was suggested to be involved in learning and retention of configural discrimination (Rudy and Sutherland, 1993), although negative findings for hippocampal involvement were also reported (Davidson et al., 1993; Whishaw and Tomie, 1995). The study of Rudy and Sutherland (1993) used negative configuration in which each elemental stimulus predicted reward, and simultaneous presentation of those two stimuli predicted no reward, which was comparable to that in the present study. Furthermore, it has been reported that the perirhinal/entorhinal (Murray et al., 1993; Higuchi et al., 1995) and the frontal cortices (Gaffan and Harrison, 1991; Whishaw et al., 1992) are essential for within-modal or cross-modal stimulus-stimulus association. The MD receives af- ferent inputs not only from the amygdala but also from the these cortices (Groenewegen, 1988). The present neurophysiological results along with these anatomical findings strongly suggest MD involvement in configural learning.

It has been reported that associative learning between objects and reinforcements was disturbed by lesions of the MD, the amygdala, or the orbital prefrontal cortex (Gaffan et al., 1993). Lesions of each of these three structures in both human and infrahuman species also resulted in similar changes in emotionality (Butter and Snyder, 1972; Waring and Means, 1976; Markowitsch, 1982). Furthermore, these three areas have intimate reciprocal connections (Krettek and Price, 1977; GoldmanRakic and Porrino, 1985; Russchen et al., 1987; Ray and Price, 1992). On the basis of these anatomical and functional similarities, these three structures have been proposed to constitute "the basolateral limbic circuit" (Krettek and Price, 1977; Sarter and Markowitsch, 1983, 1984; Bachevalier and Mishkin, 1986; Cassell and Wright, 1986; Gaffan et al., 1993) and might function as a stimulus-significance (i.e., reward-contingency) decoding circuit.

Finally, a large population $(76.1 \%)$ of the MD neurons were nonresponsive in the present study, which is consistent with the previous neurophysiological study reporting that $>90 \%$ of the monkey MD neurons were nonresponsive (Kubota et al., 1972). The MD has been implicated in various functions, consistent with 
its complex anatomical connections (see introductory remarks): not only sensory (auditory and visual), emotional, and motor functions, as indicated in the present study, but also olfactory and nociceptive functions (Andersen, 1986; Palestini et al., 1987; Staubli et al., 1987; Slotnick and Risser, 1990). Additional studies using other sensory stimuli and/or task paradigms are required to elucidate fully the functions of the MD.

\section{REFERENCES}

Aggleton JP, Mishkin M (1983) Visual recognition impairment following medial thalamic lesions in monkeys. Neuropsychologia 21:189-197.

Aggleton JP, Mishkin M (1984) Projection of the amygdala to the thalamus in the cynomolgus monkey. J Comp Neurol 222:56-68.

Andersen E (1986) Periaqueductal gray and cerebral cortex modulate responses of medial thalamic neurons to noxious stimulation. Brain Res 375:30-36.

Bachevalier J, Mishkin M (1986) Visual recognition impairment follows ventromedial but not dorsolateral prefrontal lesions in monkey. Behav Brain Res 20:249-261.

Butter CM, Snyder DR (1972) Alternations in aversive and aggressive behaviors following orbital frontal lesions in rhesus monkeys. Acta Neurobiol Exp 32:525-565.

Cassell MD, Wright DJ (1986) Topography of projections from the medial prefrontal cortex to the amygdala in the rat. Brain Res Bull 17:321-333.

Davidson TL, McKernan MG, Jarrard LE (1993) Hippocampal lesions do not impair negative patterning: a challenge to configural association theory. Behav Neurosci 107:227-234.

Davis M (1992) The role of the amygdala in conditioned fear. In: The amygdala: neurobiological aspects of emotion, memory, and mental dysfunction (Aggleton JP, ed), pp 255-305. New York: Wiley.

Davis M (1994) The role of the amygdala in emotional learning. Int Rev Neurobiol 36:225-266.

Drevets W (1995) PET and the functional anatomy of major depression. In: Emotion, memory and behavior (Nakajima T, Ono T, eds), pp 43-62. Tokyo: Japan Scientific.

Everitt BJ, Cador M, Robbins TW (1989) Interactions between the amygdala and ventral striatum in stimulus-reward associations: studies using second-order schedule of sexual reinforcement. Neuroscience 30:63-75.

Fahy FL, Riches IP, Brown MW (1993) Neuronal signals of importance to the performance of visual recognition memory task: evidence from recordings of single neurons in the medial thalamus of primates. Prog Brain Res 95:401-416.

Falls WA, Davis M (1995) Lesions of the central nucleus of the amygdala block conditioned excitation, but not conditioned inhibition of fear as measured with the fear-potentiated startle effect. Behav Neurosci 109:379-387.

Funahashi S, Bruce CJ, Goldman-Rakic PS (1990) Visuospatial coding in primate prefrontal neurons revealed by oculomotor paradigms. J Neurophysiol 63:814-831.

Funahashi S, Bruce CJ, Goldman-Rakic PS (1991) Neuronal activity related to saccadic eye movements in the monkey's dorsolateral prefrontal cortex. J Neurophysiol 65:1464-1483.

Fuster JM, Alexander GE (1973) Firing changes in cells of the nucleus medialis dorsalis associated with delayed response behavior. Brain Res 61:79-91.

Gaffan D, Harrison S (1987) Amygdalectomy and disconnection in visual learning for auditory secondary reinforcement by monkeys. J Neurosci 7:2285-2292.

Gaffan D, Harrison S (1991) Auditory-visual associations, hemispheric specialization and temporal-frontal interaction in the rhesus monkey. Brain 114:2133-2144.

Gaffan D, Murray EA (1990) Amygdalar interaction with the mediodorsal nucleus of the thalamus and the ventromedial prefrontal cortex in stimulus-reward associative learning in the monkey. J Neurosci 10:3479-3493.

Gaffan D, Murray EA, Fabre-Thorpe M (1993) Interaction of the amygdala with the frontal lobe in reward memory. Eur J Neurosci 5:968-975.

Goldman-Rakic PS, Porrino LJ (1985) The primate mediodorsal (MD) nucleus and its projection to the frontal lobe. J Comp Neurol 242:535-560.

Graff-Radford N, Damasio H, Yamada T, Eslinger PJ, Damasio AR (1985) Nonhemorrhagic thalamic infarction. Brain 108:485-516.
Groenewegen HJ (1988) Organization of the afferent connections of the mediodorsal thalamic nucleus in the rat, related to the mediodorsalprefrontal topography. Neuroscience 24:379-431.

Groenewegen HJ, Berendse HW, Wolters JG, Lohman AHM (1990) The anatomical relationship of the prefrontal cortex with the striatopallidal system, the thalamus and the amygdala: evidence for a parallel organization. Prog Brain Res 85:95-116.

Higuchi S, Zhou X, Konishi S, Hasegawa I, Miyashita Y (1995) Disruption of rhinal backward signals impairs visual associative coding of the inferotemporal neurons in monkeys. Soc Neurosci Abstr 47:10.

Hikosaka O, Wurtz RH (1983) Visual and oculomotor functions of monkey substantia nigra pars reticulata. III. Memory contingent visual and saccade response. J Neurophysiol 49:1268-1284.

Hikosaka O, Sakamoto M, Usui S (1989) Functional properties of monkey caudate neurons. I. Activities related to saccadic eye movements. J Neurophysiol 61:780-798.

Isseroff A, Rosvold HE, Galkin TW, Goldman-Rakic PS (1982) Spatial memory impairments following damage to the mediodorsal nucleus of the thalamus in rhesus monkeys. Brain Res 232:97-113.

Kim M, McGaugh JL (1992) Effects of intra-amygdala injections of NMDA receptor antagonists on acquisition and retention of inhibitory avoidance. Brain Res 585:35-48.

Krettek JE, Price JL (1977) The cortical projections of the mediodorsal nucleus and adjacent thalamic nuclei in the rat. J Comp Neurol 171:157-192.

Kurata K, Tanji J (1986) Premotor cortex neurons in macaques: activity before distal and proximal forelimb movements. J Neurosci 6:403-411.

Kubota K, Hamada I (1978) Visual tracking and neuron activity in the post-arcuate area in monkey. J Physiol (Paris) 74:297-313.

Kubota K, Niki H, Goto A (1972) Thalamic unit activity and delayed alternation performance in the monkey. Acta Neurobiol Exp 32:177-192.

Kubota Y, Gabriel M (1995) Studies of the limbic comparator: limbic circuit training-induced unit activity and avoidance behavior in rabbits with anterior dorsal thalamic lesions. Behav Neurosci 109:258-277.

Kuroda M, Price JL (1991a) Synaptic organization of projections from basal forebrain structures to the mediodorsal thalamic nucleus of the rat. J Comp Neurol 303:513-533.

Kuroda M, Price JL (1991b) Ultrastructure and synaptic organizations of axon terminals from brainstem structures to the mediodorsal thalamic nucleus of the rat. J Comp Neurol 313:539-552.

Lamarre Y, Busby L, Spidalieri G (1983) Fast ballistic arm movements triggered by visual, auditory, and somesthetic stimuli in the monkey. I. Activity of precentral cortical neurons. J Neurophysiol 50:1343-1358.

LeDoux JE (1987) Emotion. In: Handbook of physiology. I. The nervous system, Vol 5 (Mountcastle VB, ed), pp 419-459. Bethesda, MD: American Physiological Society.

Le Gros Clark WE (1932a) The structure and connections of the thalamus. Brain 55:406-470.

Le Gros Clark WE (1932b) An experimental study of thalamic connections in the rat. Philos Trans R Soc Lond [Biol] 221:1-28.

Leonard CM (1969) The prefrontal cortex of the rat. Brain Res 12:321-343.

Liles SL (1985) Activity of neurons in the putamen during active and passive movements of wrist. J Neurophysiol 53:217-236.

Markowitsch HJ (1982) Thalamic mediodorsal nucleus and memory: a critical evaluation of studies in animals and man. Neurosci Biobehav Rev 6:351-380.

Miserendino MJD, Sananes CB, Melia KR, Davis M (1990) Blocking of acquisition but not expression of conditioned fear-potentiated startle by NMDA antagonists in the amygdala. Nature 345:716-718.

Mishkin M, Aggleton JP (1981) Multiple functional contributions of the amygdala in the monkey. In: The amygdaloid complex (Ben-Ari Y, ed), pp 409-420. Amsterdam: Elsevier/North-Holland Biomedical.

Mitchell SJ, Richardson RT, Baker FH, DeLong MR (1987) The primate globus pallidus: neuronal activity related to direction of movement. Exp Brain Res 68:491-505.

Murray EA, Gaffan D, Mishkin M (1993) Neural substrates of visual stimulus-stimulus association in rhesus monkeys. $\mathrm{J}$ Neurosci 13:4549-4561.

Nishijo H, Norgren R (1990) Responses from parabrachial gustatory neurons in behaving rats. J Neurophysiol 63:707-724.

Nishijo H, Norgren R (1991) Parabrachial neuronal activity during licking by rats. J Neurophysiol 66:974-985. 
Nishijo H, Ono T, Nishino H (1988a) Topographic distribution of modality-specific amygdalar neurons in alert monkey. $\mathrm{J}$ Neurosci $8: 3556-3569$.

Nishijo H, Ono T, Nishino H (1988b) Single neuron responses in amygdala of alert monkey during complex sensory stimulation with effective significance. J Neurosci 8:3570-3583.

Ono T, Sasaki K, Nakamura K, Norgren R (1985) Integrated lateral hypothalamic neural responses to natural and artificial rewards and cue signals in the rat. Brain Res 327:303-306.

Palestini M, Mariotti M, Velasco JM, Formenti A, Mancia M (1987) Medialis dorsalis thalamic unitary response to tooth pulp stimulation and its conditioning by brainstem and limbic activation. Neurosci Lett 78:161-165.

Paxinos G, Watson C (1986) The rat brain in stereotaxic coordinates, 2nd Ed. San Diego: Academic.

Peinado-Manzano MA, Pozo-Garcia R (1991) The role of different nuclei of the thalamus in processing episodic information. Behav Brain Res 45:17-27.

Ray JP, Price JL (1992) The organization of the thalamocortical connections of the mediodorsal thalamic nucleus in the rat, related to the ventral forebrain-prefrontal cortex topography. J Comp Neurol 323:167-197.

Rudy JW, Sutherland RJ (1993) The hippocampal formation is necessary for rats to learn and remember configural discriminations. Behav Brain Res 34:97-109.

Russchen FT, Amaral DG, Price JL (1987) The afferent input to the magnocellular division of the mediodorsal thalamic nucleus in the monkey, Macaca fascicularis. J Comp Neurol 256:175-210.

Sarter M, Markowitsch HJ (1983) Convergence of basolateral amygdaloid and mediodorsal thalamic projections in different areas of the frontal cortex in the rat. Brain Res Bull 10:607-622.

Sarter M, Markowitsch HJ (1984) Collateral innervation of the medial and lateral prefrontal cortex by amygdaloid, thalamic, and brain-stem neurons. J Comp Neurol 224:445-460.

Schulman S (1957) Bilateral symmetrical degeneration of the thalamus: a clinico-pathological study. J Neuropathol Exp Neurol 16:446-470.
Shima K, Aya K, Mushiake H, Inase M, Aizawa H, Tanji J (1991) Two movement-related foci in the primate cingulate cortex observed in signal-triggered and self-paced forelimb movements. J Neurophysiol 65:188-202.

Slotnick BM, Risser JM (1990) Odor memory and learning in rats with lesions of the lateral olfactory tract and mediodorsal thalamic nucleus. Brain Res 529:23-29.

Squire LR, Moore RY (1979) Dorsal thalamic lesion in a noted case of human memory dysfunction. Ann Neurol 6:503-506.

Staubli U, Schottler F, Nejat-Bina D (1987) Role of dorsomedial thalamic nucleus and piriform cortex in processing olfactory information. Behav Brain Res 25:117-129.

Stokes KA, Best PJ (1990) Mediodorsal thalamic lesions impair "reference" and "working" memory in rats. Physiol Behav 47:471-476.

Tanji J, Kurata K (1982) Comparison of movement-related activity in two cortical motor areas of primates. J Neurophysiol 48:633-653.

Uwano T, Nishijo H, Ono T, Tamura R (1995) Neuronal responsiveness to various sensory stimuli, and associative learning in the rat amygdala. Neuroscience 68:339-361.

Victor M, Adams RD, Collins GH (1971) The Wernicke-Korsakoff Syndrome. Philadelphia: Davis.

Waring AE, Means LW (1976) The effect of medial thalamic lesions on emotionality, activity, and discrimination learning in the rat. Physiol Behav 17:181-186.

Weiskrantz L (1956) Behavioral changes associated with ablation of the amygdaloid complex in monkeys. J Comp Physiol Psychol 49:381-391.

Whishaw IQ, Tomie JA (1995) Rats with fimbria-fornix lesions can acquire and retain a visual-tactile transwitching (configural) task. Behav Neurosci 109:607-612.

Whishaw IQ, Tomie JA, Kolb B (1992) Ventrolateral prefrontal cortex lesions in rats impair the acquisition and retention of a tactile-olfactory configural task. Behav Neurosci 106:597-603.

Zola-Morgan S, Squire LR (1985) Amnesia in monkeys after lesions of the mediodorsal nucleus of the thalamus. Ann Neurol 17:558-564. 